\title{
Biosynthesis of Silver and Gold Nanoparticles Using Aqueous Extract from Crinum latifolium Leaf and Their Applications Forward Antibacterial Effect and Wastewater Treatment
}

\author{
Thanh-Truc Vo, ${ }^{1}$ Thi Thanh-Ngan Nguyen, ${ }^{2,3}$ Thi Thanh-Tam Huynh, ${ }^{3}$ Thi Thuy-Trang Vo, ${ }^{4}$ \\ Thi Thuy-Nhung Nguyen, ${ }^{4}$ Dinh-Truong Nguyen, ${ }^{4}$ Van-Su Dang, ${ }^{5}$ Chi-Hien Dang, ${ }^{1,3}$ \\ and Thanh-Danh Nguyen $\mathbb{D}^{2,3}$ \\ ${ }^{1}$ Graduate University of Science and Technology, Vietnam Academy of Science and Technology, 18 Hoang Quoc Viet, Cau Giay, \\ Hanoi, Vietnam \\ ${ }^{2}$ Institute of Research and Development, Duy Tan University, Da Nang, Vietnam \\ ${ }^{3}$ Institute of Chemical Technology, Vietnam Academy of Science and Technology, 1 Mac Dinh Chi Street, District 1, \\ Ho Chi Minh City, Vietnam \\ ${ }^{4}$ School of Biotechnology, Tan Tao University, Long An, Vietnam \\ ${ }^{5}$ Department of Chemical Technology, Ho Chi Minh City University of Food Industry, Ho Chi Minh City, Vietnam
}

Correspondence should be addressed to Thanh-Danh Nguyen; danh5463bd@yahoo.com

Received 13 March 2019; Revised 14 May 2019; Accepted 20 August 2019; Published 15 September 2019

Academic Editor: Ana Espinosa

Copyright ( 2019 Thanh-Truc Vo et al. This is an open access article distributed under the Creative Commons Attribution License, which permits unrestricted use, distribution, and reproduction in any medium, provided the original work is properly cited.

Crinum latifolium (CL) leaf is a source of various biologically active compounds such as alkaloid and phenolic compounds, which exhibit anti-inflammatory, antitumor, and antimicrobial effects. In the purpose of expanding applications for the field of bionanotechnology, we report biosynthesis of silver nanoparticles (AgNPs) and gold nanoparticles (AuNPs) by using aqueous extract from C. latifolium leaf and explore antibacterial activity and catalytic performance for degradation of pollutants. The formation of CL-AgNPs and CL-AuNPs is confirmed and optimized by UV-visible spectroscopy with surface plasmon resonance (SPR) peaks at around 402 and $539 \mathrm{~nm}$, respectively. The spherical CL-AgNPs have an average diameter of $20.5 \mathrm{~nm}$ and the multishaped CL-AuNPs possess an average size of $17.6 \mathrm{~nm}$. The actions of four bacterial strains were strongly inhibited by using the CL-AgNPs. Furthermore, the biosynthesized metallic nanoparticles (MNPs) exhibited the excellent catalytic degradation performance of pollutants.

\section{Introduction}

There are increased interests in the fabrication of MNPs due to their numerous applications. MNPs are well known as molecules acting in biomaterials, imaging, catalyst, and electrochemical applications [1-6]. Among them, AgNPs and AuNPs are the most promising owing to their physiochemical properties which significantly depend on the size and shape. In the traditional synthesis of AgNPs and AuNPs, reducing agents such as sodium borohydride and hydrazine and capping agents are usually required to maintain the size and shape of MNPs. It reveals many disadvantages including expensive cost and harmfulness towards the environment and biological framework. Alternative syntheses like using microorganisms [7] and enzymes [8] have adopted an ecofriendly approach that reduces the chemical agents, which are potentially hazardous to the environment and human health. Among them, the approach using plant extracts for the synthesis of MNPs is over other biological processes because it offers significant advantages such as lower cost of production, low toxicity, and large-scale synthesis without involving high pressure and energy conditions [9-11]. Although the mechanism of MNP biosynthesis by plant extracts is not yet completely understood, the components 
such as phenolics, terpenoids, glycosides, alkaloids, and proteins were mainly responsible for reduction and stabilization of biosynthesized MNPs [12, 13].

At the nanoscale, the metals provide many highly active uncoordinated sites because the number of active atoms on the surface is much higher than that in the core [14]. Therefore, MNPs were widely used within catalysis of organic reactions such as cross-coupling and degradation of pollutant dyes. Many recent studies showed that the biosynthesized MNPs have been used effectively for degradation of organic dye pollutants in aqueous medium $[15,16]$. It should be noted that the catalytic activity of MNPs strongly depends on the reductants and the capping agents which are responsible to prevent the agglomeration [17].

C. latifolium, a herbaceous perennial flowering plant in the amaryllis family, grows naturally in Asia, from India through Southeast Asia to south China. It has been well known as Vietnamese traditional medicine for the management of allergic disorders and tumor diseases. Its extracts have exhibited various bioactivities such as antitumor, antiviral, and antibacterial effects $[18,19]$. C. latifolium is rich in alkaloid, glucoside, and flavonoid content that could be an excellent source to synthesize AgNPs and AuNPs [20-22]. In this study, we have synthesized and characterized AgNPs and AuNPs using aqueous extract of C. latifolium leaf. The optimized MNPs were studied for antibacterial potential and catalytic degradation of pollutants in aqueous medium.

\section{Experimental}

2.1. Materials. Silver nitrate $\left(\mathrm{AgNO}_{3}\right)$, hydrogen tetrachloroaurate (III) hydrate $\left(\mathrm{HAuCl}_{4} \cdot 3 \mathrm{H}_{2} \mathrm{O}\right)$, sodium tetrahydridoborate $\left(\mathrm{NaBH}_{4}\right)$, 4-nitrophenol (4-NP), methyl orange (MO), and rhodamine B (RhB) were purchased from Acros (Belgium). C. latifolium leaves were provided by Khai Minh Macrobiotics (Ho Chi Minh City).

2.2. Plant Extract Preparation. The C. latifolium leaves were dried in air atmosphere and finely grinded up with a size of 1-2 mm by using an electronic blender. The resulting powder $(10 \mathrm{~g})$ was refluxed with distilled water $(100 \mathrm{~mL})$ for $1 \mathrm{~h}$. The mixture was filtered, and the brown filtrate was storable in the refrigerator at $4^{\circ} \mathrm{C}$ for further studies.

2.3. Biosynthesis and Optimization of Silver and Gold Nanoparticles. The C. latifolium extract was placed in solutions of $\mathrm{Ag}^{+}$or $\mathrm{Au}^{3+}$ ions under stirring in a dark condition at $1200 \mathrm{rpm}$. The formation of MNPs was clearly observed by changing in the color. Optimization of reaction parameters including concentration of metallic ions $(0.5$, $1.0,1.5$, and $2.0 \mathrm{mM}$ ), the reaction temperature (in range of $\left.30-120^{\circ} \mathrm{C}\right)$, and the reaction time $(180 \mathrm{~min})$ was explored through measurement of $\mathrm{UV}-\mathrm{V}$ is spectra from a range of 200 to $800 \mathrm{~nm}$. Reduction of ions $\mathrm{Ag}^{+}$and $\mathrm{Au}^{3+}$ by the plant extract induced increase of absorbance at the peaks of around $400 \mathrm{~nm}$ and $540 \mathrm{~nm}$, respectively. For further studies, the CLAgNPs and CL-AuNPs were biosynthesized in the optimized conditions. The solid MNPs were obtained by centrifugation at $10000 \mathrm{rpm}$ for $10 \mathrm{~min}$ and washed thrice with water to remove metallic ions and the impurities. Finally, the dried powder of MNPs was obtained after heating overnight at $90^{\circ} \mathrm{C}$ in an oven.

\subsection{Physicochemical Characterization of Silver and Gold} Nanoparticles. Absorption spectra were determined by a JASCO V-630 spectrophotometer (USA). The functional groups of organic compounds from the aqueous extract were identified by the Fourier transform infrared (FTIR), Bruker, Tensor 27 FTIR spectrophotometer (Germany). $\mathrm{X}$-ray diffraction (XRD) patterns of MNPs were recorded on X-ray diffractometer, Bruker, Model D8 ADVANCE (Germany). Transmission electronic microscopy (TEM), Hitachi H8100, and high-resolution transmission electronic microscopy (HRTEM), JEOL JEM2100, were used to analyze the morphology and crystal structure of the nanoparticles. Chemical elements were analyzed by energy dispersive X-ray spectroscopy (EDX) (EMAX ENERGY EX-400, HORIBA). The particle size and zeta potential of the MNP solutions were measured by using nanoPartica Horiba SZ-100 (Japan). Simultaneous thermogravimetry (TG) analysis and differential thermal analysis (DTA) were measured using A LabSys evo S60/58988 thermal analyzer (SETARAM, France) in a temperature range from room temperature to $800^{\circ} \mathrm{C}$ at a heating rate of $10^{\circ} \mathrm{C} / \mathrm{min}$ in the air atmosphere.

2.5. Antibacterial Activity of Silver and Gold Nanoparticles. The procedure for the biotest was carried out via the disk diffusion method as previously reported [23]. Two Grampositive bacterium strains (Bacillus subtilis, Staphylococcus aureus) and two Gram-negative bacterium strains (Escherichia coli, Agrobacterium tumefaciens) procured originally from the School of Biotechnology, Tan Tao University, Vietnam, were used to test the antibacterial activity of the biosynthesized CL-AgNPs and CL-AuNPs. The standard antibiotic ampicillin $(0.01 \mathrm{mg} / \mathrm{mL})$ and Luria Bertani broth were used as positive and negative controls, respectively. Antibacterial activity was determined by diameters of the inhibition zone around the paper disks in millimeters.

2.6. Catalytic Activity of Silver and Gold Nanoparticles. The catalytic activities of CL-AgNPs and CL-AuNPs were determined by catalytic degradation of pollutants with an excess amount of $\mathrm{NaBH}_{4}$ at the room temperature. Briefly, the mixture containing the pollutants $(2.5 \mathrm{~mL}, 0.1 \mathrm{mM})$ and $\mathrm{NaBH}_{4}(0.5 \mathrm{~mL}, 0.1 \mathrm{M})$ was added into the quartz cells. Then, the catalyst $(1 \mathrm{mg})$ was added into the reaction mixture. The degradation of pollutants was monitored by UV-Vis spectrophotometer which might record a rapid decrease in absorbance of 4-NP, MO, and RhB at peaks of 400, 464, and $554 \mathrm{~nm}$, respectively. Because this work used excess concentration of $\mathrm{NaBH}_{4}$ and very low amount of catalysts, the influence of both the factors might be reduced for the kinetical investigation. The catalytic degradation of the pollutants should be considered as a pseudo-first-order reaction calculated by the equation $\ln \left(A_{t} / A_{0}\right)=-k t$, where $k$ is the rate constant, $t$ is the reaction time, $\left(A_{0}\right)$ is the initial 

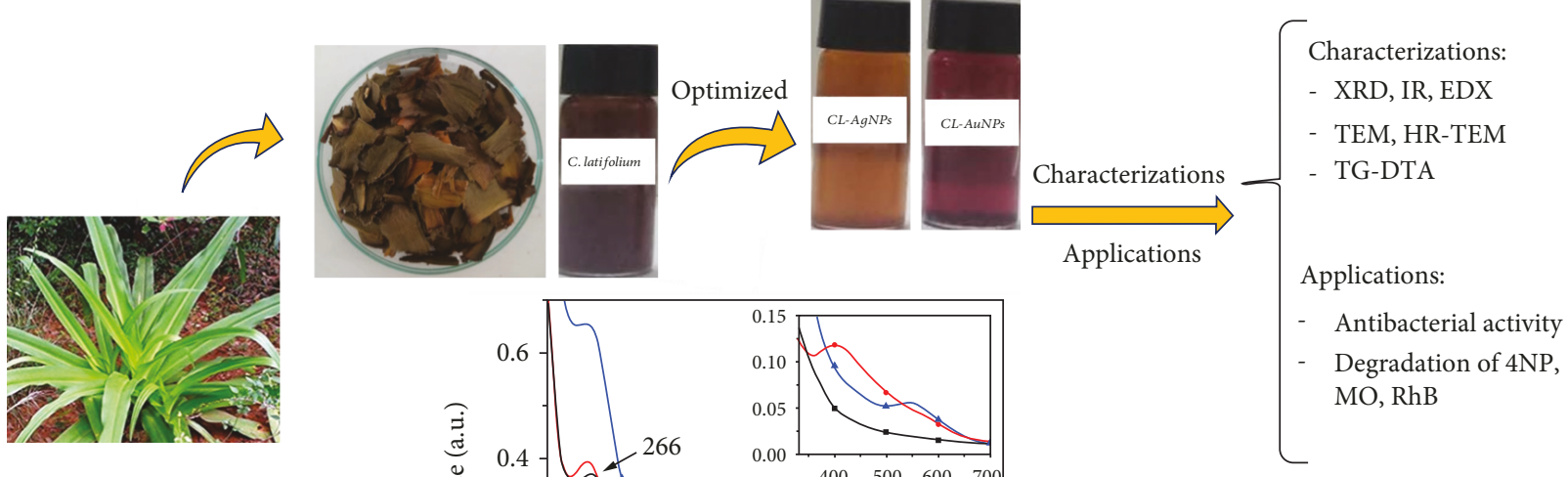

Figure 1: Schematic illustration of biosynthesis of CL-AgNPs and CL-AuNPs from aqueous extract of C. latifolium.

concentration of the corresponding pollutants, and $\left(A_{t}\right)$ is the concentration at time " $t$." The pseudo-first-order rate constant, $k$, can be directly determined from the slope of the straight line generated by plots of $\ln \left(A_{t} / A_{0}\right)$ versus the reaction time [24].

\section{Results and Discussion}

3.1. Biosynthesis of Silver and Gold Nanoparticles. C. latifolium leaves contain large contents of active molecules including phenolic antioxidants that are responsible for the reduction of MNPs [25]. Therefore, the aqueous extract of C. latifolium leaves expected as a bioactive source can be used for environmentally friendly synthesis of MNPs. In the route of this work as illustrated in Figure 1, the leaves were dried in an oven and refluxed with water for $2 \mathrm{~h}$. A brown solution was obtained after the completed filtering process. Optimization of stable MNP formation might be carried out by change of the reaction conditions including concentration of metallic ions, reaction temperature, and reaction time. The formation of the nanoparticles could be confirmed by colored change of the solution and UV-Vis measurement. The yellow and purple colloid solutions were observed for CL-AgNPs and CLAuNPs, respectively. The UV-Vis spectra showed that the extract of $C$. latifolium leaves possessed an intensive peak at $266 \mathrm{~nm}$ which might relate to $\pi \rightarrow \pi *$ transition of aromatic compounds [26, 27]. The colloidal solutions of CL-AgNPs and CL-AuNPs showed the surface plasmon resonance (SPR) bands characterized at 402 and $539 \mathrm{~nm}$, respectively. In the next step, MNPs were purified by washing with water and collected by using centrifugation. Finally, the biosynthesized nanoparticles were characterized by physicochemical analytical techniques and applied for evaluation of antibacterial and catalytic activities.

3.2. Optimization of Reaction Parameters. The shape and size of MNPs stabilized by plant extract strongly depend on the reduction of the metallic ions into the nanoparticles. The optimization of three parameters including the concentration of metallic ions, reaction temperature, and reaction time can be performed by recording changes in absorbance and $\lambda_{\max }$ values of SPR absorption bands in the UV-Vis spectra.

UV-Vis spectra and plots of $\lambda_{\max }$ and absorbance values of the biosynthesized CL-AgNPs are described in Figure 2. The results showed that the influence of AgNP formation is as a function of concentrations of $\mathrm{Ag}^{+}$ions (Figure 2(a)). When the salt concentration was concentrated, almost no change in $\lambda_{\max }$ values of the SPR band was observed. It can be attributed to no change of the sizes of AgNPs formed in the colloidal solution. However, change in absorbance of the SPR bands can clearly recognized in the absorption spectra. A maximum value of absorption density was found at the salt concentration of $1.0 \mathrm{mM}$. Reduction of absorbance at the concentration of $2.0 \mathrm{mM}$ can relate to the agglomeration of AgNPs in the colloidal solution. In fact, the solids formed can be observed during the reaction process at these concentrations.

The influence of reaction temperature was investigated in a temperature range of $30-90^{\circ} \mathrm{C}$. Figure 2 (b) shows that reaction temperature affects significantly the formation of AgNPs. The results revealed that absorbance of the SPR band grows with the increase of the temperature. At the low temperature range $\left(30-60^{\circ} \mathrm{C}\right)$, no clear peak of the SPR band was found, indicating that the reduction did not occur at this 


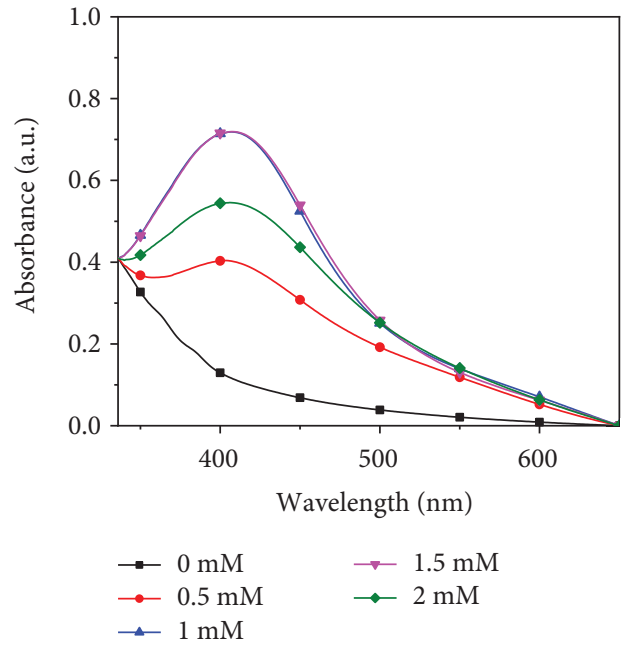

(a)

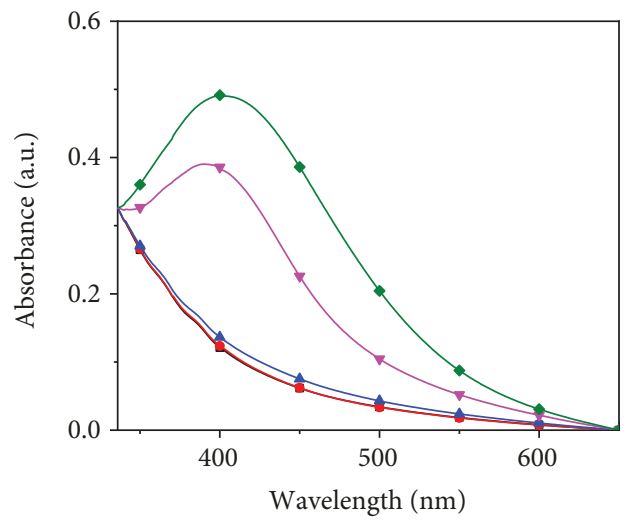

$$
\begin{aligned}
& =30^{\circ} \mathrm{C} \quad \rightarrow 75^{\circ} \mathrm{C} \\
& \rightarrow 45^{\circ} \mathrm{C} \\
& \longrightarrow 60^{\circ} \mathrm{C}
\end{aligned}
$$

(c)

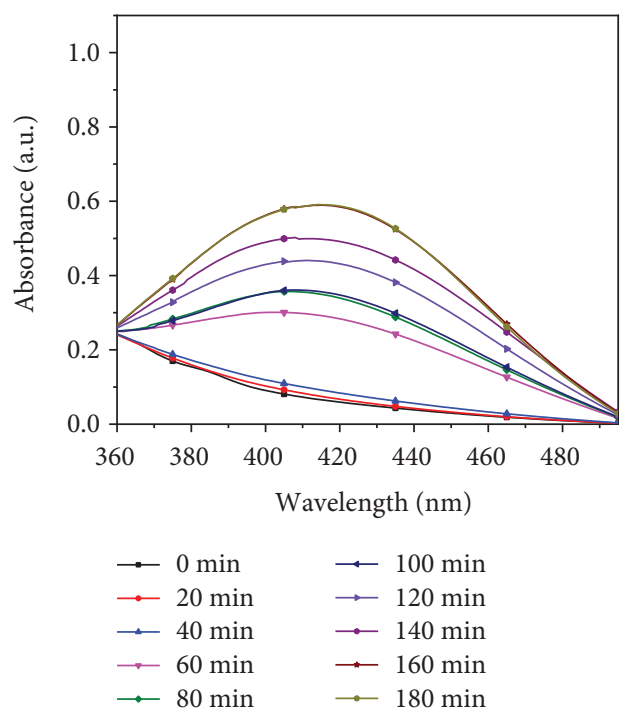

(e)

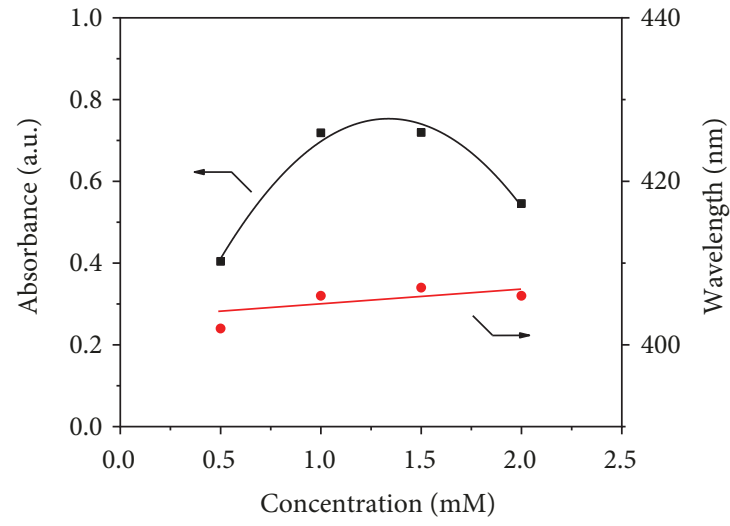

(b)

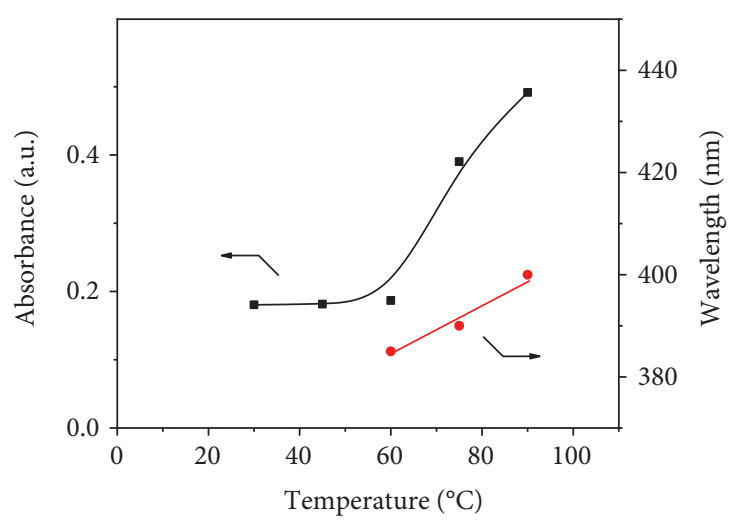

(d)

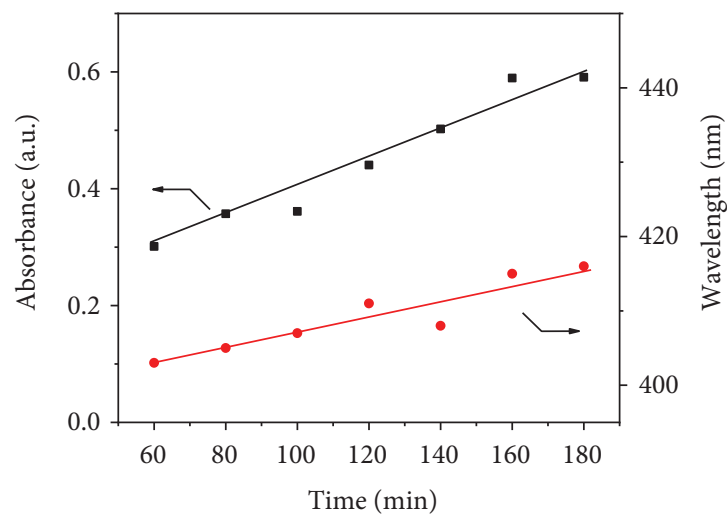

(f)

FIGURE 2: UV-Vis spectra (a, c, e) and plots of parameters versus wavelength and absorbance values $(b, d, f):(a, b)$ concentrations of Ag ${ }^{+}$ solution, $(c, d)$ reaction temperature, and $(e, f)$ reaction time. 


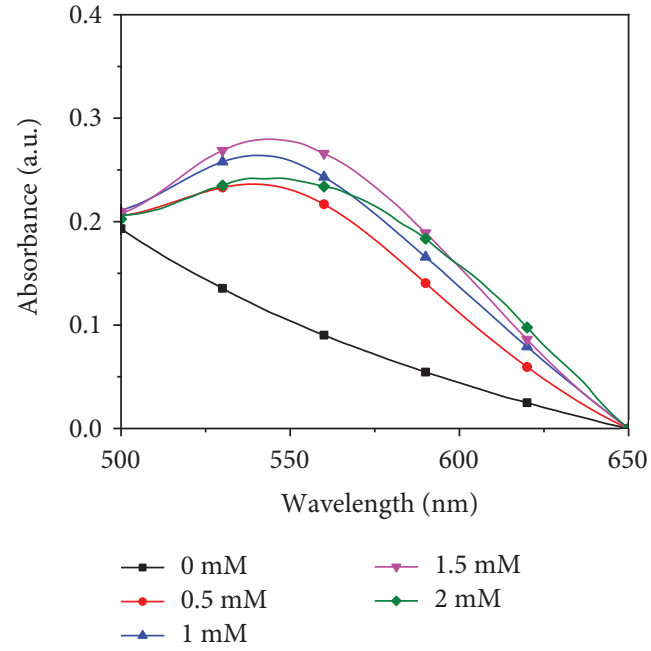

(a)

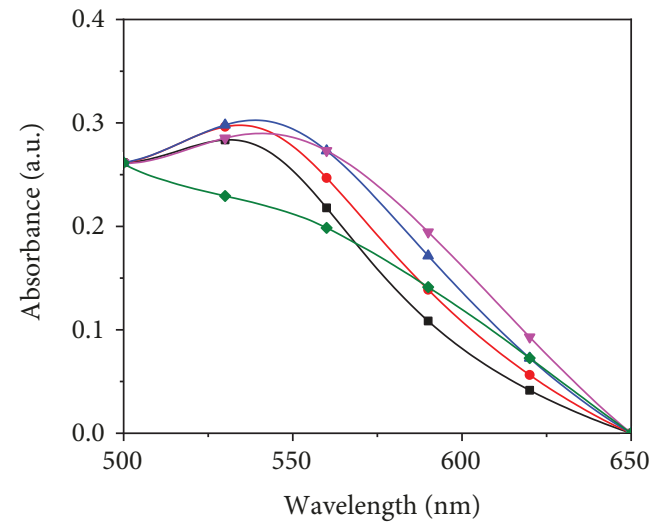

$$
\begin{aligned}
& \rightarrow 30^{\circ} \mathrm{C} \rightarrow 75^{\circ} \mathrm{C} \\
& \rightarrow 45^{\circ} \mathrm{C} \quad \rightarrow-90^{\circ} \mathrm{C} \\
& \simeq 60^{\circ} \mathrm{C}
\end{aligned}
$$

(c)

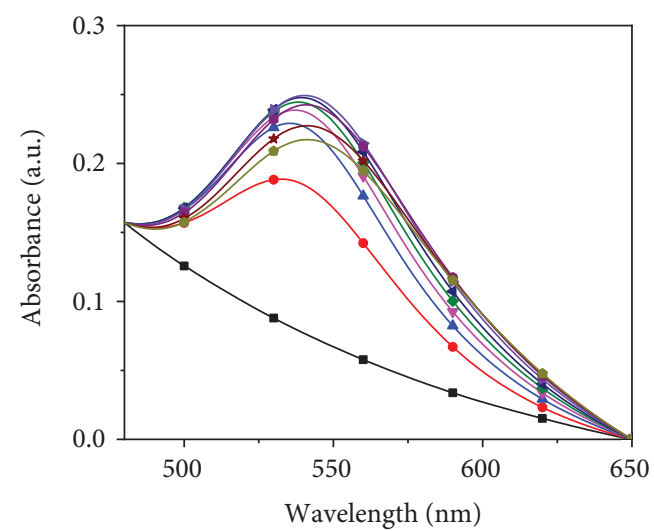

$$
\begin{array}{ll}
\rightarrow 0 \mathrm{~min} & \rightarrow 100 \mathrm{~min} \\
\rightarrow-20 \mathrm{~min} & \rightarrow-120 \mathrm{~min} \\
\rightarrow-40 \mathrm{~min} & \rightarrow-140 \mathrm{~min} \\
\rightarrow 60 \mathrm{~min} & \rightarrow-160 \mathrm{~min} \\
\rightarrow-80 \mathrm{~min} & \rightarrow-180 \mathrm{~min}
\end{array}
$$

(e)

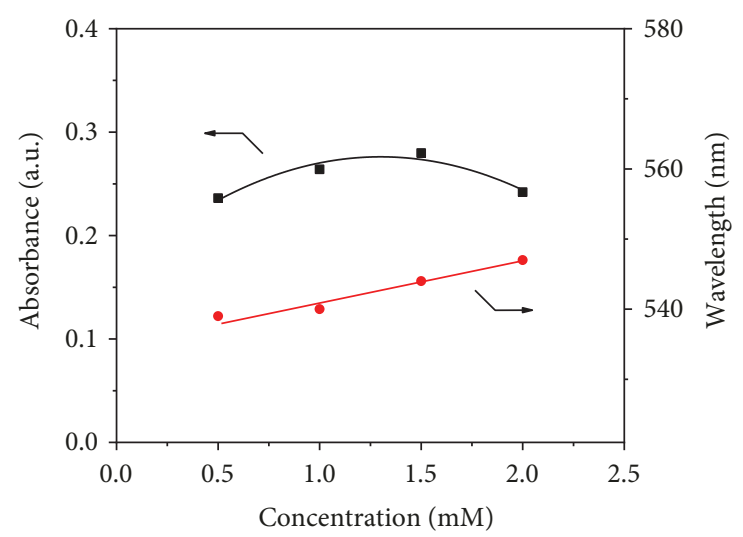

(b)

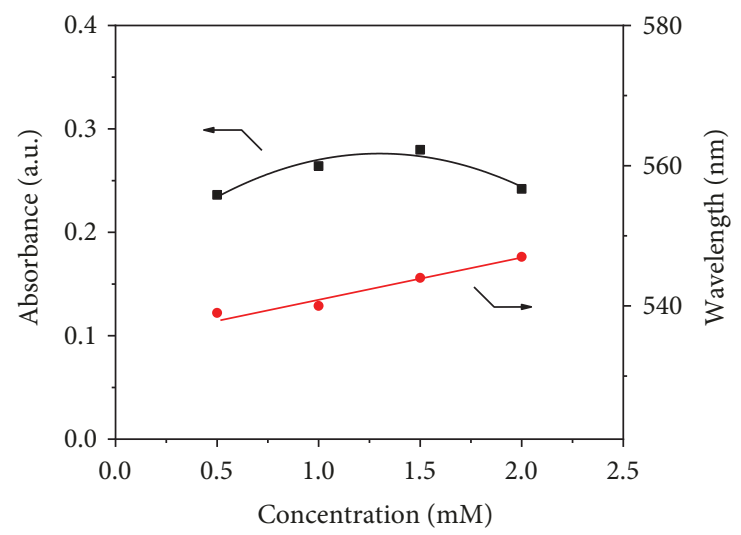

(d)

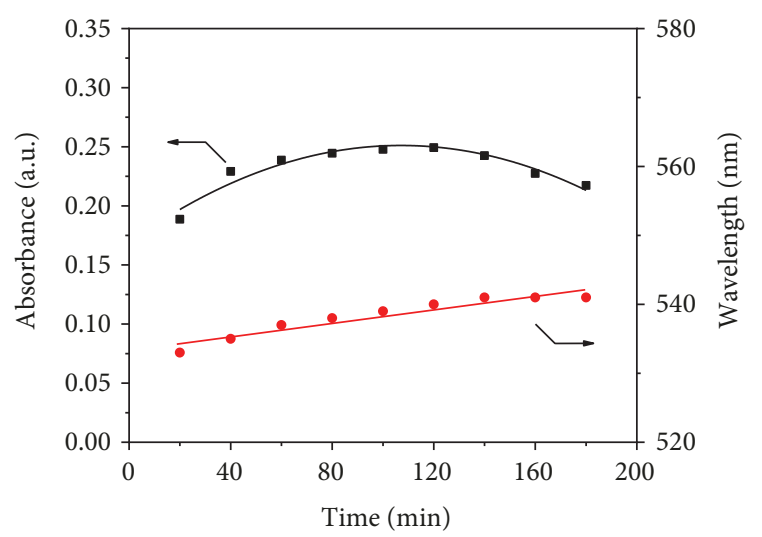

(f)

FIGURE 3: UV-Vis spectra (a, c, e) and plots of parameters versus wavelength and absorbance values $(b, d, f):(a, b)$ concentrations of Au ${ }^{3+}$ solution, $(c, d)$ reaction temperature, and $(e, f)$ reaction time. 
temperature range. A significant red shift with the high temperatures was observed, reflecting that the reaction temperature might induce an increase of the sizes and shapes of the formed AgNPs.

For studies on the effect of reaction time, UV-Vis spectra of the reaction were measured for each regular time interval of $20 \mathrm{~min}$. Figure 2(c) showed that intensive SPR peaks were not observed during initial $40 \mathrm{~min}$. After this period, the absorbance increased with the reaction time and a maximum intensity was found to be within $160 \mathrm{~min}$. A red shift of $\lambda_{\max }$ values from 403 to $416 \mathrm{~nm}$ was observed when the reaction time was increased from $60 \mathrm{~min}$ to $160 \mathrm{~min}$. It might relate changes in the size of AgNPs.

Optimization of CL-AuNP biosynthesis bases on similar studies of CL-AgNPs. Trends in synthesis of AuNPs using the C. latifolium extract significantly differed from the results of AgNP biosynthesis. For the effect of the salt concentration, absorbance of the SPR band (around $540 \mathrm{~nm}$ ) grows with increasing concentration values and a maximum value of the absorbance was observed at concentration of $1.5 \mathrm{mM}$ (Figure 3(a)). Unlike the biosynthesis of CL-AgNPs, a red shift from 539 to $547 \mathrm{~nm}$ was found when concentration was increased in a range of $0.5-2.0 \mathrm{mM}$. It indicates that the salt concentration can induce changes in the size and shape of AuNPs.

Considerably, clear SPR bands of AuNPs appeared at all reaction temperatures even at $30^{\circ} \mathrm{C}$, indicating that the reduction of gold ions can be carried out more easily in comparison with AgNP formation. It can be because the standard reduction potential of AuNPs is more than that of AgNPs [28]. A red shift of the SPR peaks was observed with increasing reaction temperature which might relate to changes in the size and shape of AuNPs. Absorbance of the SPR band achieved a maximum value at $60^{\circ} \mathrm{C}$, and a decrease of absorbance was observed at high temperatures, indicating the reduction of AuNP concentration in the colloidal solution at these temperatures. It is due to precipitation of AuNPs from the colloidal solution during the heating process.

For the effect of the reaction time, biosynthesis of CLAuNPs also showed more rapid conversion compared to biosynthesis of CL-AgNPs and achieved over $60 \%$ in the initial 20 min (Figure 3(c)). A decrease of absorbance and a slight red shift were observed with increasing reduction time.

Based on data of the optimization, the CL-AgNPs for further studies on their characterization and application were prepared at an $\mathrm{Ag}^{+}$ion concentration of $1.0 \mathrm{mM}$, stirred at $90^{\circ} \mathrm{C}$ within $160 \mathrm{~min}$ with a yield of $42.0 \%$ while biosynthesis of CL-AuNPs was carried out at an $\mathrm{Au}^{3+}$ ion concentration of $1.0 \mathrm{mM}$, stirred at $60^{\circ} \mathrm{C}$ in $100 \mathrm{~min}$ with a yield of $51.0 \%$.

3.3. Physicochemical Characterizations. FTIR spectra of $C$. latifolium leaf extract and biosynthesized CL-AgNPs and CL-AuNPs are described in Figure 4. All of the samples showed similar absorption bands, indicating that MNPs might be stabilized by phytoconstituents of CL extract. The absorption band characteristics of the leaf extract were observed at $3355,2918,2849,1638,1403,1300,1077,618$, and $538 \mathrm{~cm}^{-1}$ which corresponded to functional groups such as phenols (broad $\mathrm{O}-\mathrm{H}$ stretching), alkenes $(\mathrm{C}=\mathrm{C})$, alde-

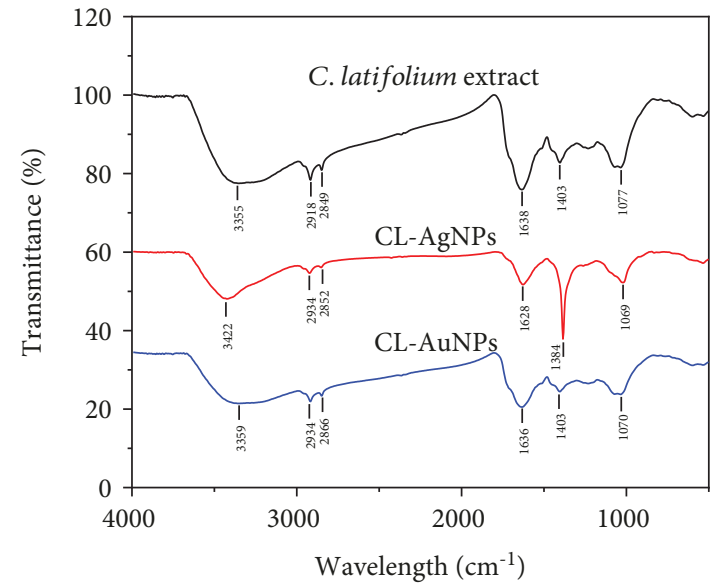

FIgURE 4: FTIR spectra of C. latifolium extract, AgNPs-CL, and AuNPs-CL.

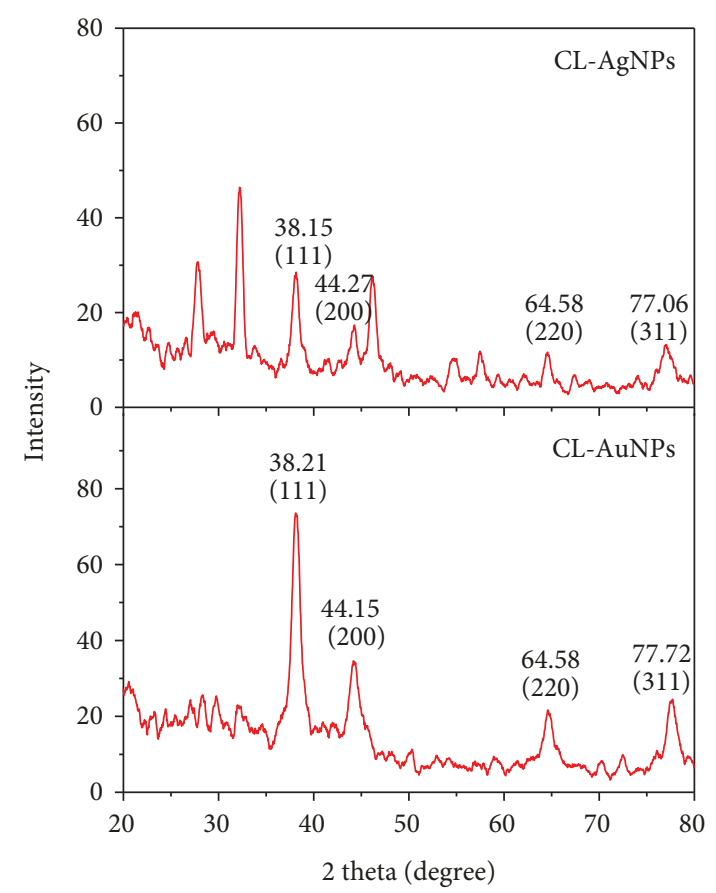

FIgURE 5: XRD pattern of synthesized CL-AgNPs (a) and CLAuNPs (b).

hydes, and primary and secondary amines or amides that play a role as the reductants in biosynthesis of MNPs [25]. These characteristic vibrations after reduction of $\mathrm{Ag}^{+}$and $\mathrm{Au}^{3+}$ ions were shifted to new peaks at 3422, 2934, 2852, $1628,1384,1262,1019$, and $534 \mathrm{~cm}^{-1}$ and $3359,2934,2866$, $1636,1403,1258,1070,598$, and $533 \mathrm{~cm}^{-1}$, respectively. It confirmed that the phytoconstituents present in the aqueous extract of $C$. latifolium leaf were responsible for the reduction of the metallic ions and stabilization of MNPs.

The crystallographic information of the biosynthesized MNPs was determined by using powder XRD analysis. The XRD patterns of CL-AgNPs and CL-AuNPs were displayed in Figure 5. The XRD spectrum of CL-AgNPs shows distinct diffraction peaks at $2 \theta$ of $38.15^{\circ}, 44.27^{\circ}, 64.58^{\circ}$, and $77.06^{\circ}$, 


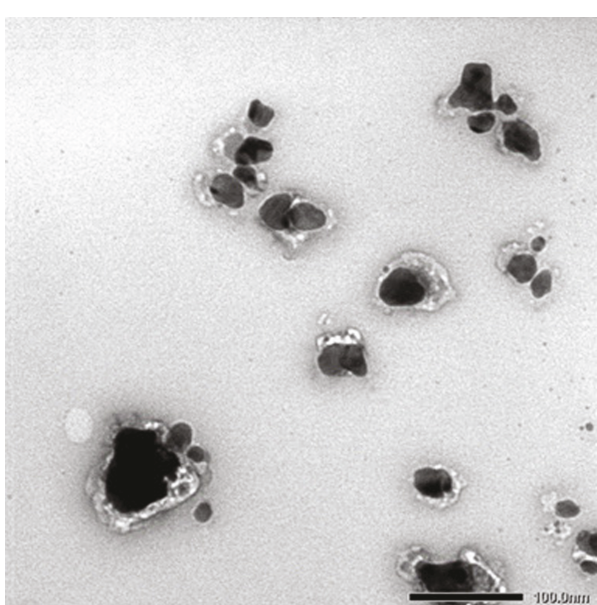

(a)

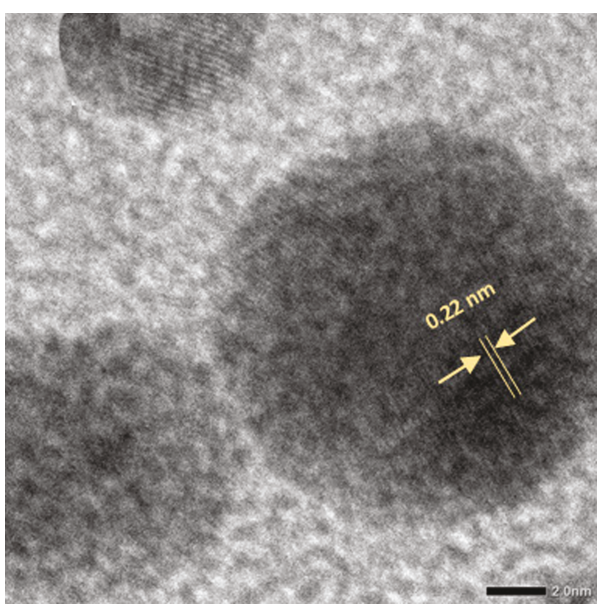

(c)

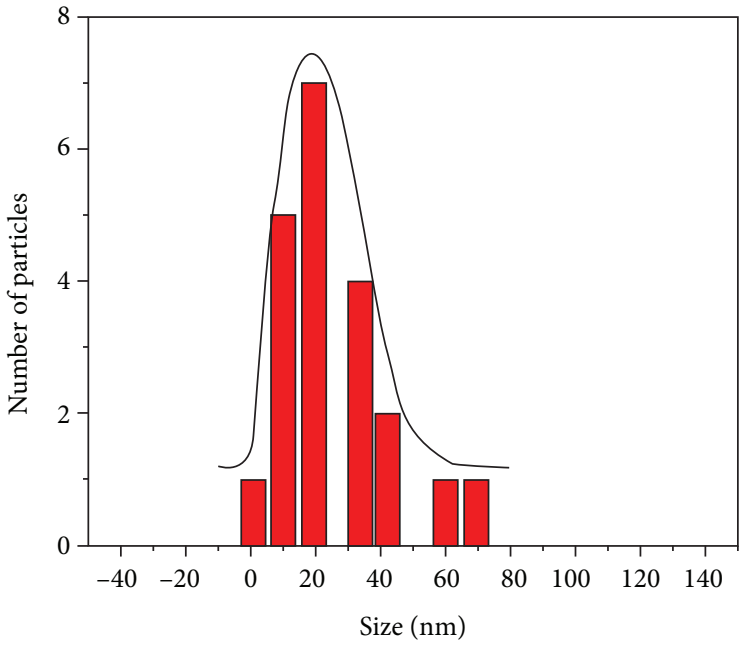

(b)

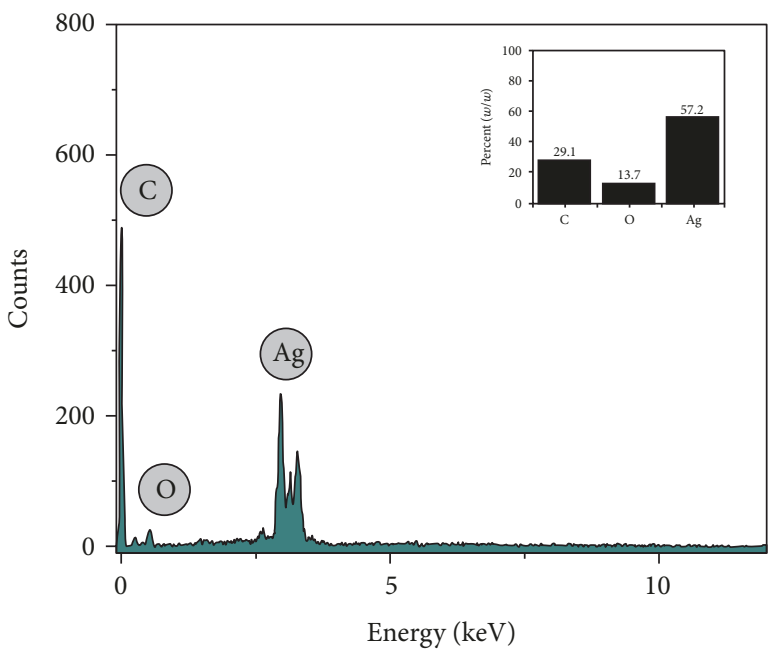

(d)

Figure 6: (a) TEM, (b) particle size distribution, (c) HRTEM, and (d) EDX spectrum and average content of elements (inset) of biosynthesized CL-AgNPs.

indexing the (111), (200), (220), and (311) planes, respectively, of the face-centered cubic Ag structure [29, 30]. The unidentified peaks at $2 \theta$ of $27.77^{\circ}, 32.21^{\circ}, 54.74^{\circ}$, and $57.47^{\circ}$ might be assigned to crystallization of the bioorganic phase on the surface of the CL-AgNP and $\mathrm{AgCl}$ crystals [31]. In the XRD spectrum of CL-AuNPs, the characteristic diffraction peaks at $2 \theta$ values of $38.2^{\circ}, 44.7^{\circ}, 66.70^{\circ}$, and $76.72^{\circ}$, which correspond to crystal planes (111), (200), (220), and (311), respectively, of the face-centered cubic structure, demonstrated that the synthesized CL-AuNPs were crystalline in nature. XRD analysis showed that the most intense signal of crystalline silver and gold nanoparticles displayed the preferential orientation of the crystals towards the (111) plane.

The morphologies of the MNPs were obtained from their microscopic images. TEM, HRTEM images, particle size distribution, and EDX data of CL-AgNPs and CL-AuNPs are given in Figures 6 and 7. The TEM image of CL-AgNPs clearly reveals the biomolecules surrounding the nanoparticles which may relate to unidentified peaks in the XRD spectrum of CL-AgNPs while a similar phenomenon is not observed in the TEM image of CL-AuNPs. The results showed that the AuNPs appear as dense particles compared to AgNPs in which the interparticle distance is great. The TEM images suggest that AgNPs are mostly spherical in shape with a mean diameter of $20.5 \mathrm{~nm}$ while the morphology of AuNPs is found to be multishaped including spherical, triangular, and octagonal shapes in an average size of $17.6 \mathrm{~nm}$. Differences in size and shape between the MNPs can relate to differences in the reduction potentials and phytochemicals of stabilized agents of MNPs [32-36]. The HRTEM images of the single nanoparticles showed clear crystal lattice of MNPs. The spacing between lattice fringes of 


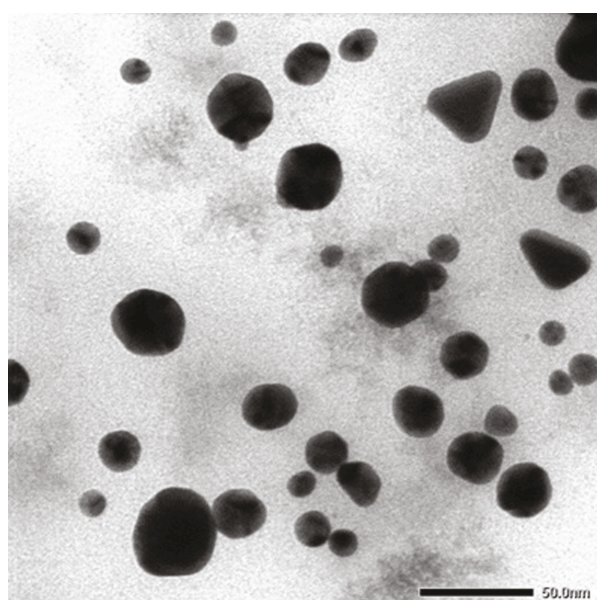

(a)

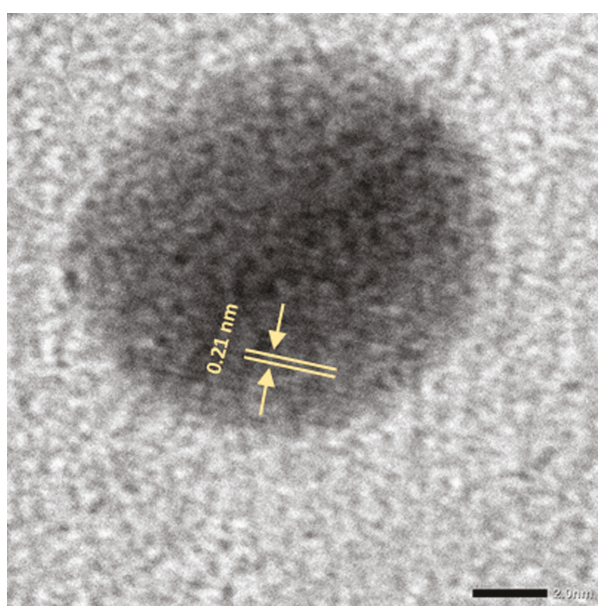

(c)

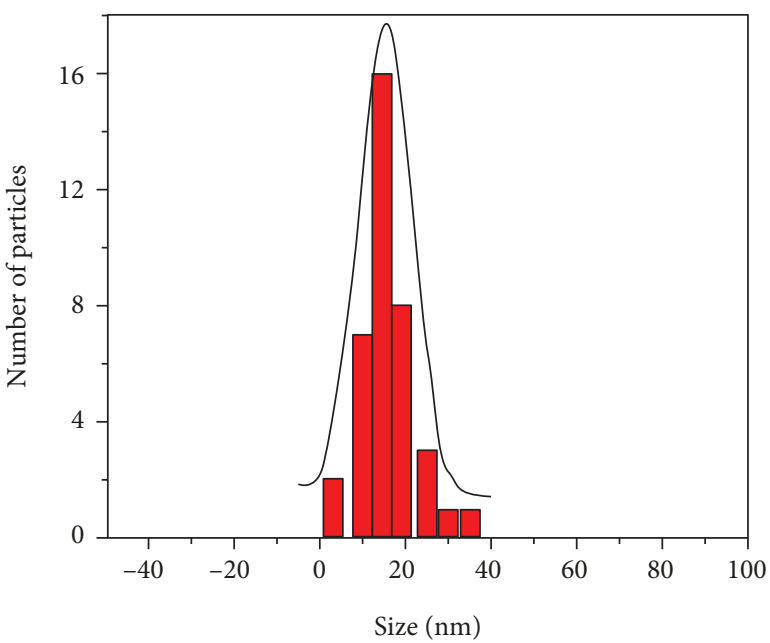

(b)

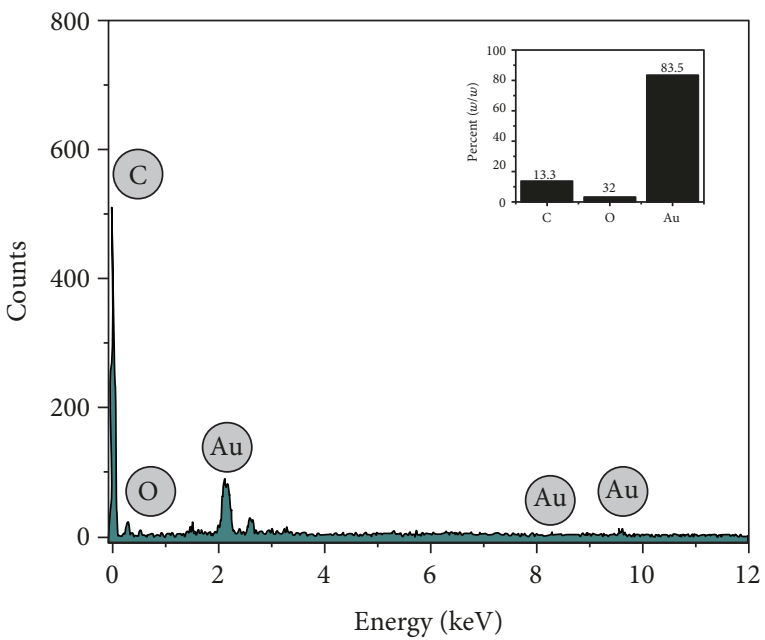

(d)

FIgUre 7: (a) TEM, (b) particle size distribution, (c) HRTEM, and (d) EDX spectrum and average content of elements (inset) of biosynthesized CL-AuNPs.

AgNPs and AuNPs was found to be 0.22 and $0.21 \mathrm{~nm}$, respectively, which indicates the growth of MNPs taking place preferentially on the (111) plane [37].

The elemental composition of nanoparticles was characterized by using EDX spectroscopy. The intensive signal of elemental silver at $2.98 \mathrm{keV}$ in the EDX spectra was observed in Figure 6(d) [26]. The high content of elemental gold was certified by three characteristic signals at 2.14, 8.35 and $9.73 \mathrm{keV}$ (Figure 7(d)). Average contents of silver in CLAgNPs and gold in CL-AuNPs were found from EDX spectra data to be $57.2 \%(w / w)$ and $83.5 \%(w / w)$, respectively.

Dynamic light scattering (DLS) measurements were done to determine the size of MNPs formed, and zeta potential was measured to evaluate the available surface charge on the MNP surface which corresponds to stability in colloidal solution as shown in Figure 8. The particle size distribution of both MNPs exhibited a monodispersity index. It showed various sizes of the particles in the CL-AgNP sample ranging from $65 \mathrm{~nm}$ to $210 \mathrm{~nm}$ with an average particle size of $115.6 \mathrm{~nm}$ while that of CL-AuNPs exhibited a bigger size ranging from 100 to $340 \mathrm{~nm}$ with an average particle size of $171.2 \mathrm{~nm}$. The difference in the particle size distribution of the colloids is due to the multicomponent nature of $C$. latifolium leaf extract that is responsible as stabilization agents for formation of corresponding MNPs [38]. Both nanoparticle types exhibited negative zeta potentials at $-19.9 \mathrm{mV}$ for CL-AgNPs and $-20.8 \mathrm{mV}$ for CL-AuNPs. High negative zeta potential values indicate that MNPs carry a sufficient surface charge to be electrostatically stabilized and resistant to spontaneous aggregation in colloidal solutions.

Thermal behaviors of the nanoparticles were investigated by simultaneous TG-DTA measurement in the air flow of $20 \mathrm{~mL} / \mathrm{min}$ in the temperature range of $30-800^{\circ} \mathrm{C}$ as shown in Figure 9. Different thermal behaviors of CL-AgNPs and 


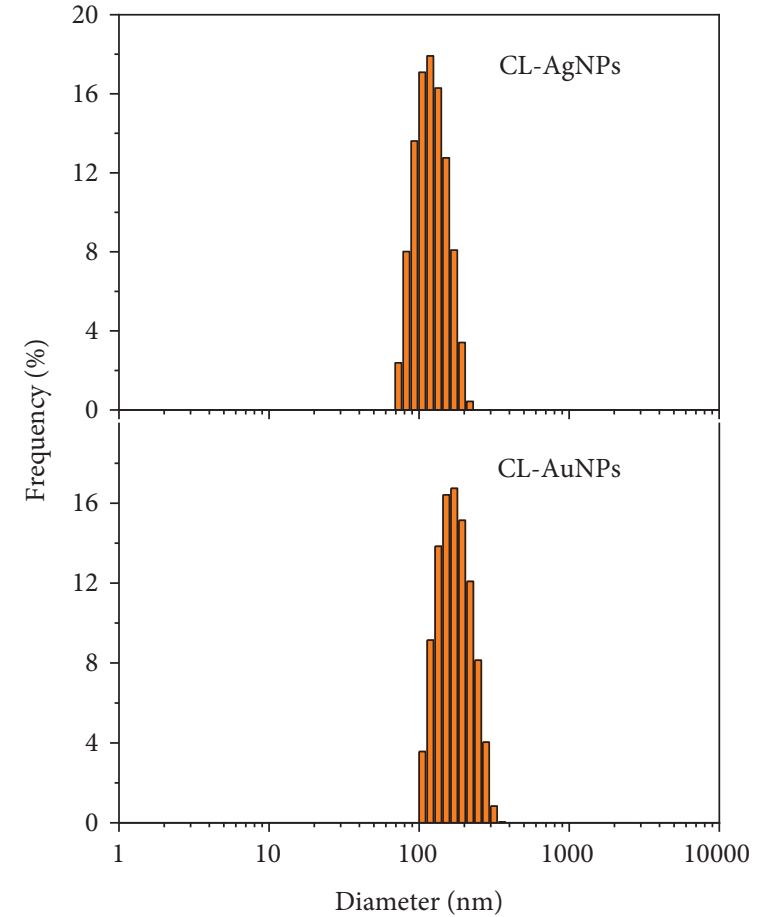

(a)

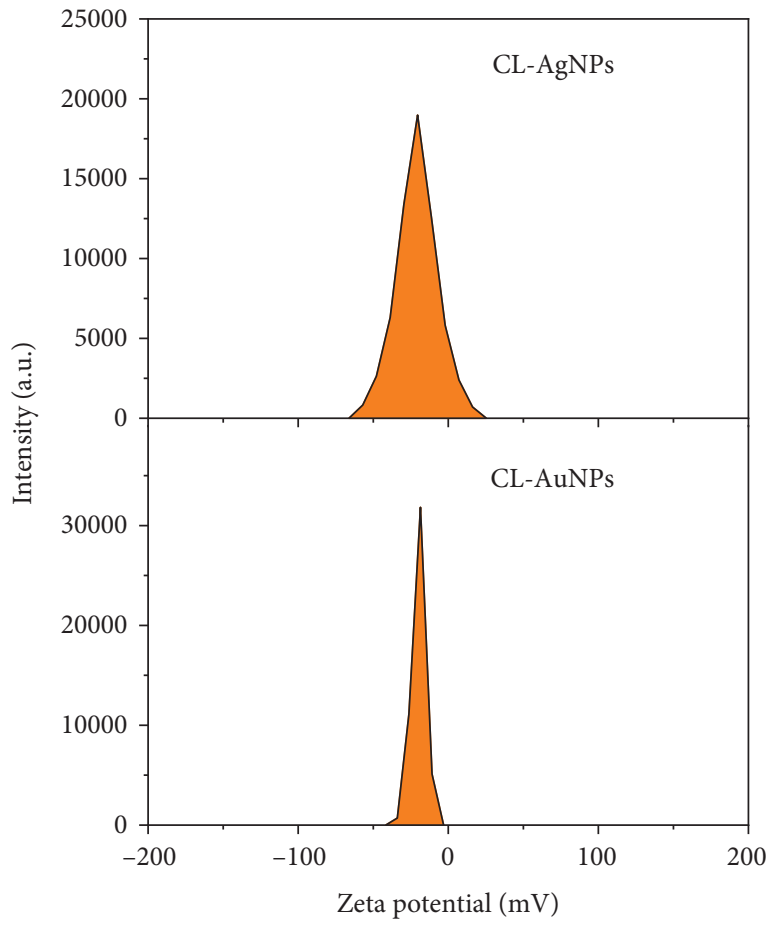

(b)

Figure 8: DLS spectra (a) and zeta potential (b) of CL-AgNPs and CL-AuNPs.

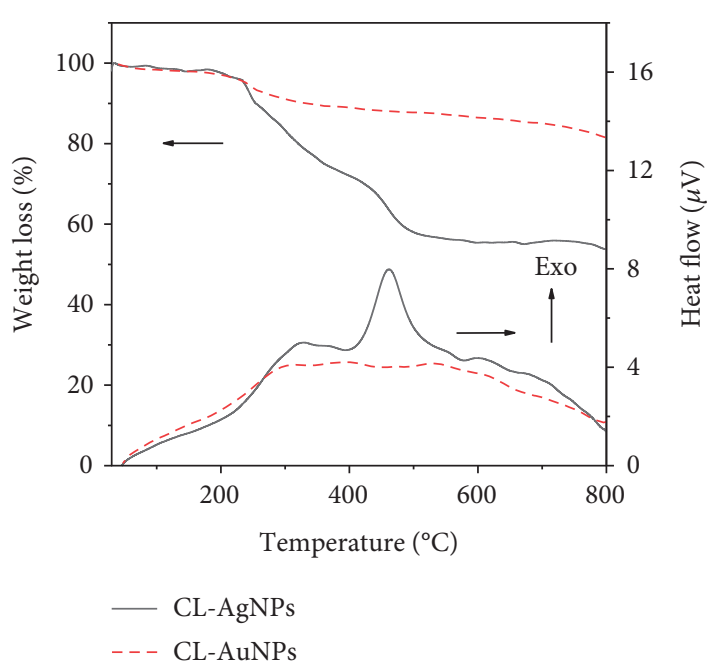

Figure 9: Simultaneous TG and DTA curves of CL-AgNPs and CLAuNPs in an air flow of $20 \mathrm{~mL} / \mathrm{min}$ at a heating rate of $10^{\circ} \mathrm{C} / \mathrm{min}$.

CL-AuNPs could be observed in TGA curves. Both the samples showed that the weight loss was not observed at a temperature below $100^{\circ} \mathrm{C}$, indicating no moisture being contained in the MNPs. The CL-AgNP sample showed mass loss taking places in three stages between 200 and $600^{\circ} \mathrm{C}$. The first stage appears at around $230^{\circ} \mathrm{C}$ (approx. $5 \%$ weight loss) while the second and third stages are observed at around $410^{\circ} \mathrm{C}$ (approx. 23\% weight loss) and around $580^{\circ} \mathrm{C}$ (approx. $18 \%$ weight loss), respectively. Thus, the total weight loss of CLAgNPs was aprox. $45 \%$. On the other hand, the TG curve of CL-AuNPs showed that the mass loss occurs in only two stages between 100 and $800^{\circ} \mathrm{C}$ accounting for $18 \%$ of the total weight. DTA curves showed exothermic peaks occurring at $318^{\circ} \mathrm{C}$ and $462^{\circ} \mathrm{C}$ for CL-AgNPs and $308^{\circ} \mathrm{C}$ for CL-AuNPs. The exothermic peaks are attributed to oxidation of organic compounds presented in the nanoparticles [39]. Data of TG analysis can determine the total amount of organic components that might be present in the plant extract and were capped and adsorbed on the MNP surface [40, 41]. Therefore, total amount of AgNPs presented in the sample can estimate from TG data about 55\% s and total amount of AgNPs is about $82 \%$. This results are supported by the calculation from EDX spectra.

3.4. Antibacterial Assay. It has been demonstrated that antibacterial activity of MNPs is strongly dependent on the size, shape, method of synthesis, and compositions of the capping agent $[42,43]$. Antibacterial activities of the biosynthesized MNPs were evaluated via a zone of inhibition assay for four microorganisms including E. coli and A. tumefaciens (Gram-negative bacteria) and B. subtilis and S. aureus (Gram-positive bacteria). The bioactivity of MNPs is investigated at various weights in a range of $0.014-0.070 \mu \mathrm{g}$. The results showed that CL-AuNPs did not exhibit antibacterial activity in the range of the tested concentrations whereas CL-AgNPs inhibited strongly all the tested bacterial strains. The antibacterial data of CL-AgNPs are illustrated in Figure 10. At a weight of $0.014 \mu \mathrm{g}$, it did not display any activity on all the tested strains and the zones of bacterial inhibition grow when increasing the concentration of AgNPs. The highest activity of CL-AgNPs was observed against two 


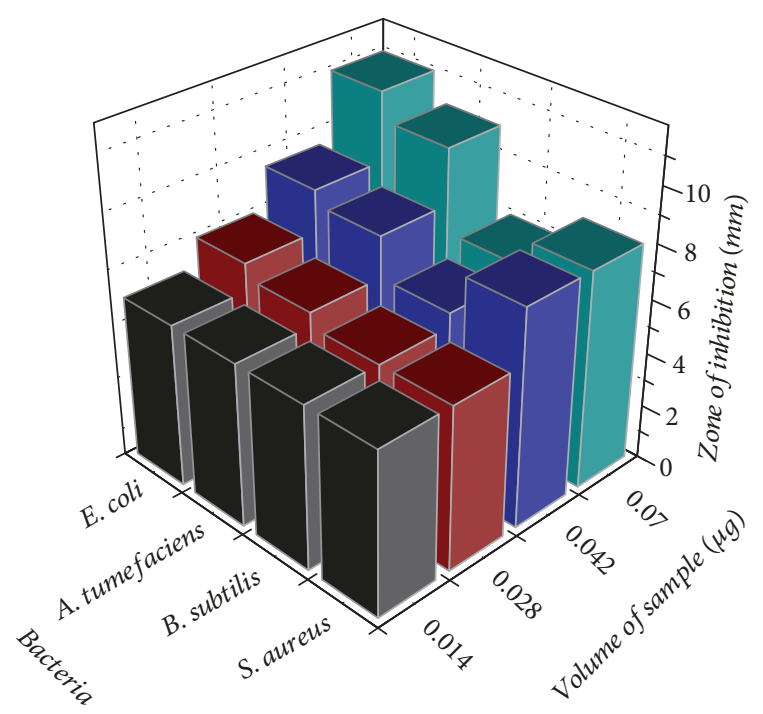

FIGURE 10: Plot of inhibition zone at the different concentrations of CL-AgNPs for various bacteria.

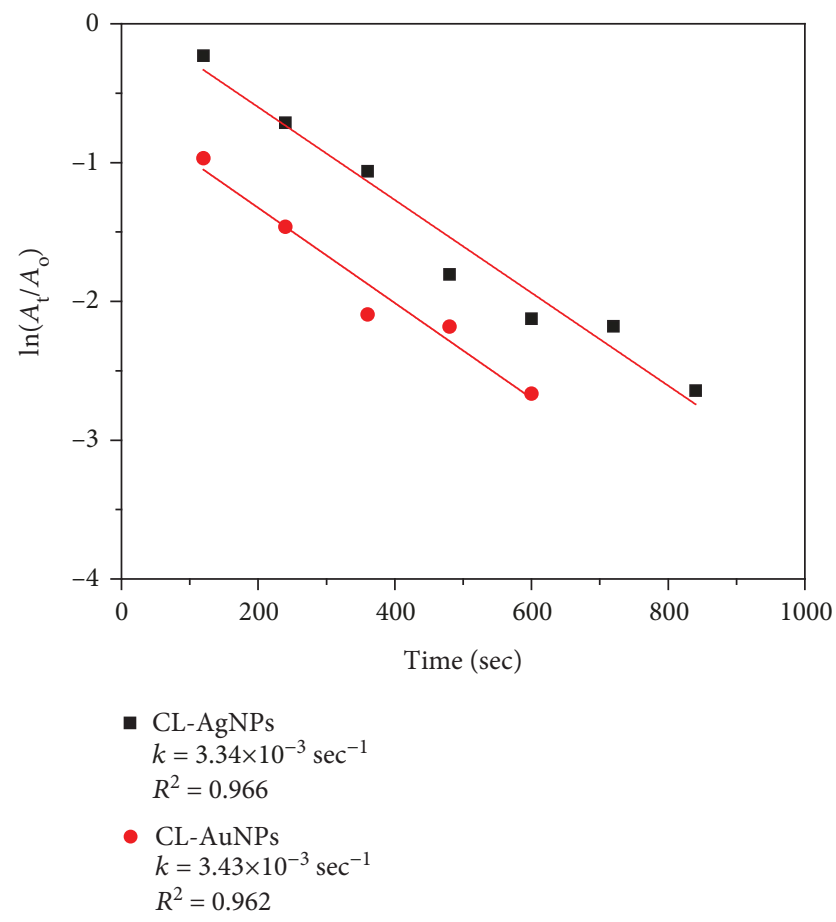

Figure 11: First-order kinetics plotted for degradation of 4nitrophenol in catalysts of CL-AgNPs and CL-AuNPs.

Gram-negative strains, E. coli and A. tumefaciens. Moreover, these results showed significantly higher activity than AgNPs biosynthesized from aqueous extract of the other plants [23, 44]. Once again, it demonstrated that the bioactivity of biogenic AgNPs is strongly affected by compositions of bioactive compounds from the plant extract.

3.5. Catalytic Performance of Nanoparticles. In recent years, removal of dye pollutants is particularly considerable for wastewater treatment in the manufacturing industry. The synthetic organic colorants are the largest group of industrial compounds in both number and amount. The present work carried out the degradation of dyes 4-NP, MO, and RhB using aqueous $\mathrm{NaBH}_{4}$ as the model reaction. It is well known as thermodynamically favorable reactions; however, due to large oxidation-reduction potential difference between donor and acceptor molecules, the kinetic barrier reduced the feasibility of this degradation [45]. In fact, the previous researches have shown very slow reaction rates without the catalyst $[26,46]$. In order to overcome this kinetic barrier, the noble metal nanoparticles are usually used to catalyze the reaction. The mechanism for degradation of dyes in the MNP catalyst has been well known as an electron transfer process that transferred electrons from the donor $\mathrm{BH}_{4}{ }^{-}$ions to the acceptor organic molecules via the MNP surface [27, 47, 48].

Because 4-NP possesses strong toxicity, high stability in aqueous environment, and resistant biodegradation, reduction of 4-NP by the $\mathrm{NaBH}_{4}$ agent in the various catalysts is widely investigated [46]. The conversion from 4-NP into 4-aminophenol (4-AP) occurs via an intermediate; 4-nitrophenolate ion and $\mathrm{NaBH}_{4}$ in aqueous solution play a role as a hydrogen source [49]. Formation of 4nitrophenolate was confirmed that the absorption maximum peak was red shifted from $317 \mathrm{~nm}$ to $400 \mathrm{~nm}$ after the addition of $\mathrm{NaBH}_{4}$ was completed. As soon as the addition of CL-AgNP and CL-AuNP catalysts into the solution was completed, disappearance of the color and a rapid decrease of absorbance at $400 \mathrm{~nm}$ are observed while a new peak concomitantly appeared at $298 \mathrm{~nm}$, indicating the formation of 4-AP. The UV-Vis spectra showed that the degradation of 4-NP in the presence of CL-AgNPs and CL-AuNPs was completed in $14 \mathrm{~min}$ and $10 \mathrm{~min}$, respectively (Figure S1). Figure 11 shows that there is a good linear relation between $\ln \left(A_{t} / A_{0}\right)$ and time $t$, demonstrating that degradation of 4-NP is followed by the pseudo-first-order reaction. The value of the kinetic rate constant in the presence of CLAgNPs $\left(3.34 \times 10^{-3} \mathrm{sec}^{-1}\right)$ was lower than that of catalyst CL-AuNPs $\left(3.34 \times 10^{-3} \mathrm{sec}^{-1}\right)$ which are comparable with some of biosynthesized MNP catalysts reported previously (Table 1). The results of the present work show that the CL-AgNPs reveal better catalytic activity than AgNPs biosynthesized from $D$. longan seed and C. occidentalis leaf extract and CL-AuNPs exhibit the higher catalytic performance in comparison with AuNPs biosynthesized from $T$. montevideense and $M$. ingens. However, the catalytic activity of both the MNPs was lower than the corresponding MNPs biosynthesized from A. lappa extract. It is evident that the catalytic efficiency of MNPs for the degradation of the pollutants is strongly dependent on the stabilizing agents.

$\mathrm{MO}$, an organic azo dye containing sulfosalt, is one of the dangerous pollutants in the water source. It can be degraded by reductants like $\mathrm{NaBH}_{4}$ to form nontoxic species [54]. The absorption band of $\mathrm{MO}$ is well known to appear at peak $465 \mathrm{~nm}$, and the reduction of MO in the presence of samples AgNPs and AuNPs can be observed from reduction of the color and absorbance as shown in Figure S2. The results 
TABLE 1: Comparison of the rate constants of biosynthesized AgNP and AuNP catalysts towards the catalytic reduction of 4-nitrophenol.

\begin{tabular}{|c|c|c|c|c|}
\hline MNPs & Biological system & Size $(\mathrm{nm})$ & Rate constant per $1 \mathrm{mg}$ of catalyst $\left(\mathrm{sec}^{-1}\right)$ & References \\
\hline \multirow{4}{*}{ AgNPs } & Dimocarpus longan seed extract & 40 & $4.7 \times 10^{-4}$ & {$[50]$} \\
\hline & Cassia occidentalis leaf extract & $5-25$ & $1.00 \times 10^{-3}$ & {$[51]$} \\
\hline & Arctium Lappa extract & 21.3 & $6.77 \times 10^{-3}$ & {$[23]$} \\
\hline & Crinum latifolium leaf extract & 20.5 & $3.34 \times 10^{-3}$ & This work \\
\hline \multirow{4}{*}{ AuNPs } & Trichosporon montevideense & $12-53$ & $5.26 \times 10^{-4}$ & {$[52]$} \\
\hline & Magnusiomyces ingens LH-F1 & 28.3 & $1.54 \times 10^{-3}$ & {$[53]$} \\
\hline & Arctium Lappa extract & 24.7 & $6.87 \times 10^{-3}$ & {$[23]$} \\
\hline & Crinum latifolium leaf extract & 17.6 & $3.43 \times 10^{-3}$ & This work \\
\hline
\end{tabular}

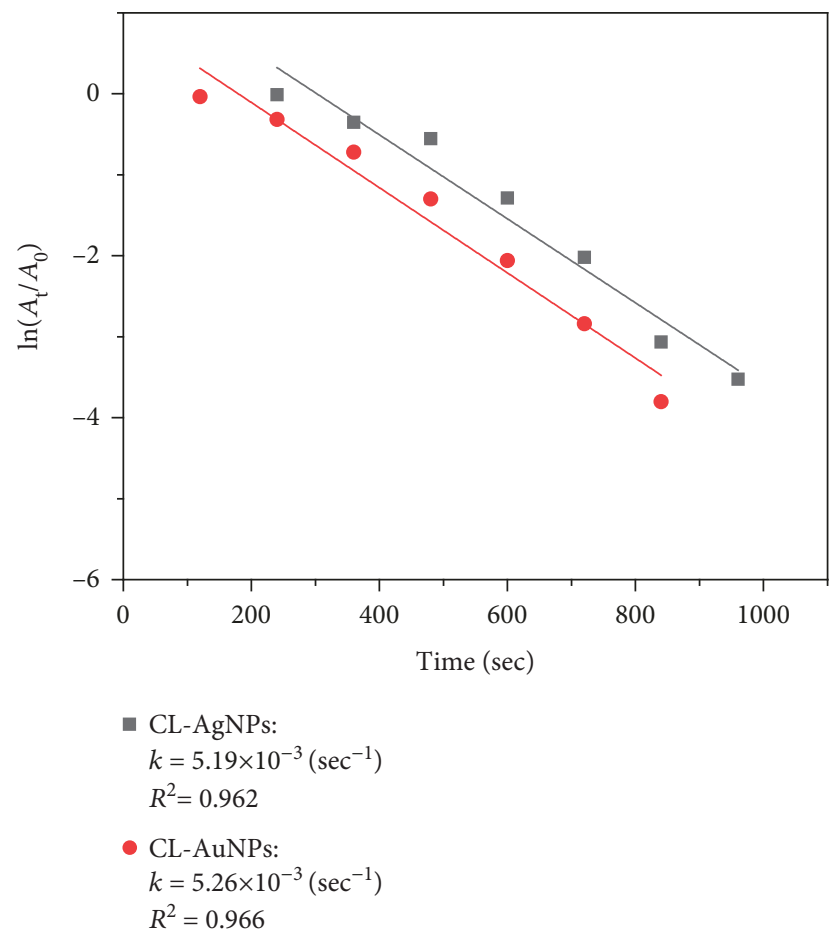

FIGURE 12: First-order kinetics plotted for degradation of methyl orange in catalysts of CL-AgNPs and CL-AuNPs.

showed that the MNPs can accelerate the reduction rate and the degradation of $\mathrm{MO}$ was completed within $16 \mathrm{~min}$ for AgNPs and 14 min for AuNPs with evidence from almost zero absorption at $465 \mathrm{~nm}$. The kinetic results showed that the good linearity between $\ln \left(A_{t} / A_{0}\right)$ and reaction time (Figure 12). The calculated $k$ value of the MO degradation in CL-AgNPs and CL-AuNPs are found to be $5.19 \times 10^{-3}$ and $5.26 \times 10^{-3} \mathrm{sec}^{-1}$, respectively.

$\mathrm{RhB}$ is widely used in the textile industry as an organic dye that forms a popular dye pollutant in industrial effluent. In the presence of the biosynthesized MNPs, degradation of RhB was observed with the gradual decrease of color intensity from pink-red to colorless. Thereafter, UV-Vis spectra could be used to determine the catalytic degradation efficiency by reducing absorbance at around $554 \mathrm{~nm}$. The spectra showed that the absorption maxima reduced completely as the

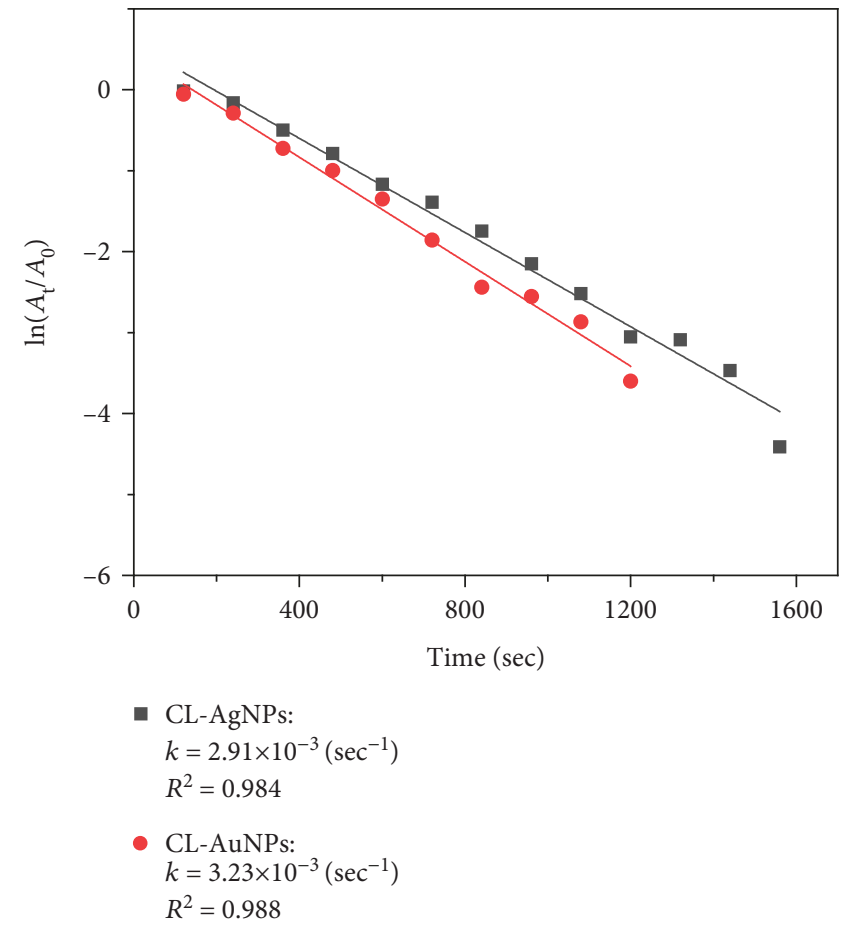

FIgURE 13: First-order kinetics plotted for degradation of rhodamine B in catalysts of AgNPs-CL and AuNPs-CL.

reaction time increased to $26 \mathrm{~min}$ for CL-AgNPs and $20 \mathrm{~min}$ for CL-AuNPs (Figure S3). The kinetic constant of the RhB reduction was calculated by the plot of the absorbance values versus the reaction time (Figure 13). The $k$ values of $\mathrm{RhB}$ degradation in the presence of CL-AgNPs and CL-AuNPs were found to be $2.91 \times 10^{-3} \mathrm{sec}^{-1}$ with a correlation coefficient value of 0.984 and $3.23 \times 10^{-3} \mathrm{sec}^{-1}$ with a correlation coefficient value of 0.988 , respectively. In general, biogenic AgNPs and AuNPs prepared from aqueous extract of C. latifolium revealed effective application potential for treatment of pollution dyes in the industrial effluent.

\section{Conclusions}

This study demonstrated the aqueous extract of Crinum latifolium leaf as both reducing and stabilizing agents for 
preparation of silver and gold nanoparticles. The developed methodology allowed to optimize and produce the MNPs with various shapes and sizes. The pure crystalline nanoparticles were characterized by using analytic techniques such as FTIR, XRD, EDX, TEM, DLS, and TGDTA. The CL-AgNPs and CL-AuNPs possessed average diameters of $20.5 \mathrm{~nm}$ and $17.6 \mathrm{~nm}$, respectively. The average content of metals could be determined by both EDX spectra and TG analysis which showed about 57.2\% $(w / w)$ for silver and about $83.5 \%(w / w)$ for gold in the samples. The antibacterial power of MNPs examined showed that the biosynthesized AgNPs have high activity in the inhibition of four tested bacterial strains. Furthermore, catalytic studies performed for reduction of the pollutants by $\mathrm{NaBH}_{4}$ indicate that the catalytic performance of biosynthesized AuNPs is better than that of AgNPs in all tests. The present study demonstrates novel MNPs biosynthesized by using aqueous extract of C. latifolium leaf which finds applications as potential antibacterial agents and advanced catalysts for the reduction of pollutants from industrial effluents.

\section{Data Availability}

The data used to support the findings of this study are included within the article.

\section{Conflicts of Interest}

The authors declare that they have no conflicts of interest.

\section{Acknowledgments}

This research is funded by the Vietnam National Foundation for Science and Technology Development (NAFOSTED) under grant number 104.99-2018.369.

\section{Supplementary Materials}

Figure S1: UV-Vis spectra for degradation of 4-nitrophenol using CL-AgNPs (A) and CL-AuNPs (B). Figure S2: UVVis spectra for degradation of methyl orange using CLAgNPs (A) and CL-AuNPs (B). Figure S3: UV-Vis spectra for degradation of rhodamine B using CL-AgNPs (A) and CLA-uNPs (B). (Supplementary Materials)

\section{References}

[1] G. Korotcenkov, S. D. Han, and J. R. Stetter, "Review of electrochemical hydrogen sensors," Chemical Reviews, vol. 109, no. 3, pp. 1402-1433, 2009.

[2] J. Han, J. Zhang, M. Yang, D. Cui, and J. M. de la Fuente, "Glucose-functionalized Au nanoprisms for optoacoustic imaging and near-infrared photothermal therapy," Nanoscale, vol. 8, no. 1, pp. 492-499, 2016.

[3] M. Hu, J. Chen, Z. Y. Li et al., "Gold nanostructures: engineering their plasmonic properties for biomedical applications," Chemical Society Reviews, vol. 35, no. 11, pp. 1084-1094, 2006.

[4] S. Satpathy, A. Patra, B. Ahirwar, and M. Delwar Hussain, "Antioxidant and anticancer activities of green synthesized silver nanoparticles using aqueous extract of tubers of Pueraria tuberosa," Artificial Cells, Nanomedicine, and Biotechnology, vol. 46, Supplement 3, pp. S71-S85, 2018.

[5] T. T. N. Le, N. H. Ly, T. D. Nguyen et al., "In situ Raman spectroscopic monitoring of organic dyes and ferric ions in Fenton reactions on sharp-edged gold nanostar surfaces," Colloids and Surfaces A: Physicochemical and Engineering Aspects, vol. 551, pp. 1-8, 2018.

[6] N. H. Ly, T. D. Nguyen, T. L. Bui, S. Lee, J. Choo, and S. W. Joo, "Spectroscopic measurements of interactions between hydrophobic 1-pyrenebutyric acid and silver colloidal nanoparticles," Colloids and Surfaces A: Physicochemical and Engineering Aspects, vol. 518, pp. 295-303, 2017.

[7] S. Gurunathan, K. Kalishwaralal, R. Vaidyanathan et al., "Biosynthesis, purification and characterization of silver nanoparticles using Escherichia coli," Colloids and Surfaces B: Biointerfaces, vol. 74, no. 1, pp. 328-335, 2009.

[8] A. Rangnekar, T. K. Sarma, A. K. Singh, J. Deka, A. Ramesh, and A. Chattopadhyay, "Retention of enzymatic activity of $\alpha$-amylase in the reductive synthesis of gold nanoparticles," Langmuir, vol. 23, no. 10, pp. 5700-5706, 2007.

[9] M. Yadi, E. Mostafavi, B. Saleh et al., "Current developments in green synthesis of metallic nanoparticles using plant extracts: a review," Artificial Cells, Nanomedicine, and Biotechnology, vol. 46, Supplement 3, pp. S336-S343, 2018.

[10] M. P. Patil and G. D. Kim, "Eco-friendly approach for nanoparticles synthesis and mechanism behind antibacterial activity of silver and anticancer activity of gold nanoparticles," Applied Microbiology and Biotechnology, vol. 101, no. 1, pp. 79-92, 2017.

[11] A. K. Mittal, Y. Chisti, and U. C. Banerjee, "Synthesis of metallic nanoparticles using plant extracts," Biotechnology Advances, vol. 31, no. 2, pp. 346-356, 2013.

[12] Y. Park, Y. N. Hong, A. Weyers, Y. S. Kim, and R. J. Linhardt, "Polysaccharides and phytochemicals: a natural reservoir for the green synthesis of gold and silver nanoparticles," IET Nanobiotechnology, vol. 5, no. 3, pp. 69-78, 2011.

[13] L. M. Carrillo-López, R. M. Soto-Hernández, H. A. ZavaletaMancera, and A. R. Vilchis-Néstor, "Study of the performance of the organic extracts of Chenopodium ambrosioides for $\mathrm{Ag}$ nanoparticle synthesis," Journal of Nanomaterials, vol. 2016, Article ID 4714162, 13 pages, 2016.

[14] F. J. Osonga, P. Le, D. Luther, L. Sakhaee, and O. A. Sadik, "Water-based synthesis of gold and silver nanoparticles with cuboidal and spherical shapes using luteolin tetraphosphate at room temperature," Environmental Science: Nano, vol. 5, no. 4, pp. 917-932, 2018.

[15] J. R. Nakkala, R. Mata, K. Raja, V. Khub Chandra, and S. R. Sadras, "Green synthesized silver nanoparticles: catalytic dye degradation, in vitro anticancer activity and in vivo toxicity in rats," Materials Science and Engineering C, vol. 91, pp. 372-381, 2018.

[16] Z. U. H. Khan, A. Khan, Y. M. Chen et al., "Enhanced antimicrobial, anti-oxidant applications of green synthesized AgNPsan acute chronic toxicity study of phenolic azo dyes \& study of materials surface using X-ray photoelectron spectroscopy," Journal of Photochemistry and Photobiology. B, vol. 180, pp. 208-217, 2018.

[17] Y. Mikami, A. Dhakshinamoorthy, M. Alvaro, and H. Garcia, "Catalytic activity of unsupported gold nanoparticles," Catalysis Science \& Technology, vol. 3, no. 1, pp. 58-69, 2013. 
[18] Y. Ding, D. Qu, K. M. Zhang et al., "Phytochemical and biological investigations of Amaryllidaceae alkaloids: a review," Journal of Asian Natural Products Research, vol. 19, no. 1, pp. 53-100, 2017.

[19] J. Refaat, M. S. Kamel, M. A. Ramadan, and A. A. Ali, "Crinum; an endless source of bioactive principles: a review. Part V. Biological profiles," International Journal of Pharmaceutical Sciences and Research, vol. 4, no. 4, pp. 1239-1252, 2013.

[20] A. Aziz, G. S. Raju, A. Das, J. Ahmed, and M. M. R. Mogha, "Evaluation of in vitro anthelmintic activity, total phenolic content and cytotoxic activity of Crinum latifolium L. (family: Amaryllidaceae)," Advanced Pharmaceutical Bulletin, vol. 4, no. 1, pp. 15-19, 2014.

[21] N. T. N. Tram, T. V. Titorenkova, V. St. Bankova, N. V. Handjieva, and S. S. Popov, "Crinum L. (Amaryllidaceae)," Fitoterapia, vol. 73, no. 3, pp. 183-208, 2002.

[22] T. T. H. Hanh, D. H. Anh, P. T. T. Huong et al., "Crinane, augustamine, and $\beta$-carboline alkaloids from Crinum latifolium," Phytochemistry Letters, vol. 24, pp. 27-30, 2018.

[23] T. T. N. Nguyen, T. T. Vo, B. N. H. Nguyen et al., "Silver and gold nanoparticles biosynthesized by aqueous extract of burdock root, Arctium Lappa as antimicrobial agent and catalyst for degradation of pollutants," Environmental Science and Pollution Research, vol. 25, no. 34, pp. 34247-34261, 2018.

[24] D. Channei, B. Inceesungvorn, N. Wetchakun et al., "Photocatalytic degradation of methyl orange by $\mathrm{CeO}_{2}$ and $\mathrm{Fe}$-doped $\mathrm{CeO}_{2}$ films under visible light irradiation," Scientific Reports, vol. 4 , no. 1, article 5757, 2014.

[25] H. Y. T. Nguyen, B. H. T. Vo, L. T. H. Nguyen et al., "Extracts of Crinum latifolium inhibit the cell viability of mouse lymph oma cell line EL4 and induce activation of anti-tumour activity of macrophages in vitro," Journal of Ethnopharmacology, vol. 149, no. 1, pp. 75-83, 2013.

[26] T. D. Nguyen, C. H. Dang, and D. T. Mai, "Biosynthesized AgNP capped on novel nanocomposite 2-hydroxypropyl- $\beta$ cyclodextrin/alginate as a catalyst for degradation of pollutants," Carbohydrate Polymers, vol. 197, pp. 29-37, 2018.

[27] T. D. Nguyen, T. T. Vo, C. H. Nguyen, V. D. Doan, and C. H. Dang, "Biogenic palladium nanoclusters supported on hybrid nanocomposite 2-hydroxypropyl- $\beta$-cyclodextrin/alginate as a recyclable catalyst in aqueous medium," Journal of Molecular Liquids, vol. 276, pp. 927-935, 2019.

[28] L. Zhao, Y. Wang, X. Zhao, Y. Deng, Q. Li, and Y. Xia, "Green preparation of ag-Au bimetallic nanoparticles supported on graphene with alginate for non-enzymatic hydrogen peroxide detection," Nanomaterials, vol. 8, no. 7, p. 507, 2018.

[29] H. Banu, N. Renuka, S. M. Faheem et al., "Gold and silver nanoparticles biomimetically synthesized using date palm pollen extract-induce apoptosis and regulate p53 and Bcl-2 expression in human breast adenocarcinoma cells," Biological Trace Element Research, vol. 186, no. 1, pp. 122-134, 2018.

[30] N. A. Sutan, D. S. Manolescu, I. Fierascu et al., "Phytosynthesis of gold and silver nanoparticles enhance in vitro antioxidant and mitostimulatory activity of Aconitum toxicum Reichenb. rhizomes alcoholic extracts," Materials Science and Engineering: $C$, vol. 93, pp. 746-758, 2018.

[31] J. Li, B. Tian, T. Li et al., "Biosynthesis of Au, Ag and Au-Ag bimetallic nanoparticles using protein extracts of Deinococcus radiodurans and evaluation of their cytotoxicity," International Journal of Nanomedicine, vol. 13, pp. 1411-1424, 2018.
[32] S. Phukan, P. Bharali, A. K. Das, and M. H. Rashid, "Phytochemical assisted synthesis of size and shape tunable gold nanoparticles and assessment of their catalytic activities," RSC Advances, vol. 6, no. 55, pp. 49307-49316, 2016.

[33] M. Ovais, A. T. Khalil, N. U. Islam et al., "Role of plant phytochemicals and microbial enzymes in biosynthesis of metallic nanoparticles," Applied Microbiology and Biotechnology, vol. 102, no. 16, pp. 6799-6814, 2018.

[34] P. Kuppusamy, M. M. Yusoff, G. P. Maniam, and N. Govindan, "Biosynthesis of metallic nanoparticles using plant derivatives and their new avenues in pharmacological applications - an updated report," Saudi Pharmaceutical Journal, vol. 24, no. 4, pp. 473-484, 2016.

[35] P. Dauthal and M. Mukhopadhyay, "Noble metal nanoparticles: plant-mediated synthesis, mechanistic aspects of synthesis, and applications," Industrial \& Engineering Chemistry Research, vol. 55, no. 36, pp. 9557-9577, 2016.

[36] S. Francis, E. P. Koshy, and B. Mathew, "Green synthesis of Stereospermum suaveolens capped silver and gold nanoparticles and assessment of their innate antioxidant, antimicrobial and antiproliferative activities," Bioprocess and Biosystems Engineering, vol. 41, no. 7, pp. 939-951, 2018.

[37] S. Mallick, P. Sanpui, S. S. Ghosh, A. Chattopadhyay, and A. Paul, "Synthesis, characterization and enhanced bactericidal action of a chitosan supported core-shell copper-silver nanoparticle composite," RSC Advances, vol. 5, no. 16, pp. 12268-12276, 2015.

[38] P. Singh, S. Pandit, J. Garnæs et al., "Green synthesis of gold and silver nanoparticles from Cannabis sativa (industrial hemp) and their capacity for biofilm inhibition," International Journal of Nanomedicine, vol. 13, pp. 3571-3591, 2018.

[39] C. H. Dang and T. D. Nguyen, "Physicochemical characterization of Robusta spent coffee ground oil for biodiesel manufacturing," Waste and Biomass Valorization, vol. 10, no. 9, pp. 2703-2712, 2019.

[40] A. A. A. Aljabali, Y. Akkam, M. S. A. Zoubi et al., "Synthesis of gold nanoparticles using leaf extract of Ziziphus zizyphus and their antimicrobial activity," Nanomaterials, vol. 8, no. 3, p. 174, 2018.

[41] M. M. H. Khalil, E. H. Ismail, K. Z. El-Baghdady, and D. Mohamed, "Green synthesis of silver nanoparticles using olive leaf extract and its antibacterial activity," Arabian Journal of Chemistry, vol. 7, no. 6, pp. 1131-1139, 2014.

[42] D. H. Kim, J. C. Park, G. E. Jeon, C. S. Kim, and J. H. Seo, "Effect of the size and shape of silver nanoparticles on bacterial growth and metabolism by monitoring optical density and fluorescence intensity," Biotechnology and Bioprocess Engineering, vol. 22, no. 2, pp. 210-217, 2017.

[43] E. Hoseinzadeh, P. Makhdoumi, P. Taha et al., "A review on nano-antimicrobials: metal nanoparticles, methods and mechanisms," Current Drug Metabolism, vol. 18, no. 2, pp. 120-128, 2017.

[44] S. Ponarulselvam, C. Panneerselvam, K. Murugan, N. Aarthi, K. Kalimuthu, and S. Thangamani, "Synthesis of silver nanoparticles using leaves of Catharanthus roseus Linn. G. Don and their antiplasmodial activities," Asian Pacific Journal of Tropical Biomedicine, vol. 2, no. 7, pp. 574-580, 2012.

[45] A. Gangula, R. Podila, R. M, L. Karanam, C. Janardhana, and A. M. Rao, "Catalytic reduction of 4-nitrophenol using biogenic gold and silver nanoparticles derived from Breynia rhamnoides," Langmuir, vol. 27, no. 24, pp. 15268-15274, 2011. 
[46] P. Zhao, X. Feng, D. Huang, G. Yang, and D. Astruc, "Basic concepts and recent advances in nitrophenol reduction by gold- and other transition metal nanoparticles," Coordination Chemistry Reviews, vol. 287, pp. 114-136, 2015.

[47] C. Kastner and A. F. Thunemann, "Catalytic reduction of 4-nitrophenol using silver nanoparticles with adjustable activity," Langmuir, vol. 32, no. 29, pp. 7383-7391, 2016.

[48] R. Begum, Z. H. Farooqi, E. Ahmed et al., "Catalytic reduction of 4-nitrophenol using silver nanoparticles-engineered poly(N-isopropylacrylamide-co-acrylamide) hybrid microgels," Applied Organometallic Chemistry, vol. 31, no. 2, article e3563, 2017.

[49] X. Kong, H. Zhu, C. L. Chen, G. Huang, and Q. Chen, "Insights into the reduction of 4-nitrophenol to 4-aminophenol on catalysts," Chemical Physics Letters, vol. 684, pp. 148-152, 2017.

[50] F. U. Khan, Y. Chen, N. U. Khan et al., "Antioxidant and catalytic applications of silver nanoparticles using Dimocarpus longan seed extract as a reducing and stabilizing agent," Journal of Photochemistry and Photobiology B, vol. 164, pp. 344351, 2016.

[51] M. Gondwal and G. Joshi nee Pant, "Synthesis and catalytic and biological activities of silver and copper nanoparticles using Cassia occidentalis," International Journal of Biomaterials, vol. 2018, Article ID 6735426, 10 pages, 2018.

[52] W. Shen, Y. Qu, X. Pei et al., "Green synthesis of gold nanoparticles by a newly isolated strain Trichosporon montevideense for catalytic hydrogenation of nitroaromatics," Biotechnology Letters, vol. 38, no. 9, pp. 1503-1508, 2016.

[53] Y. Qu, S. You, X. Zhang et al., "Biosynthesis of gold nanoparticles using cell-free extracts of Magnusiomyces ingens LH-F1 for nitrophenols reduction," Bioprocess and Biosystems Engineering, vol. 41, no. 3, pp. 359-367, 2018.

[54] V. K. Vidhu and D. Philip, "Catalytic degradation of organic dyes using biosynthesized silver nanoparticles," Micron, vol. 56, pp. 54-62, 2014. 


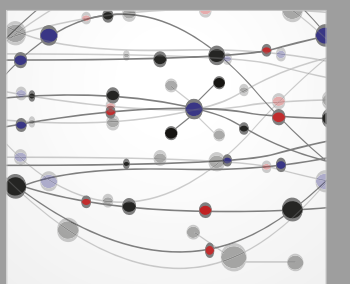

The Scientific World Journal
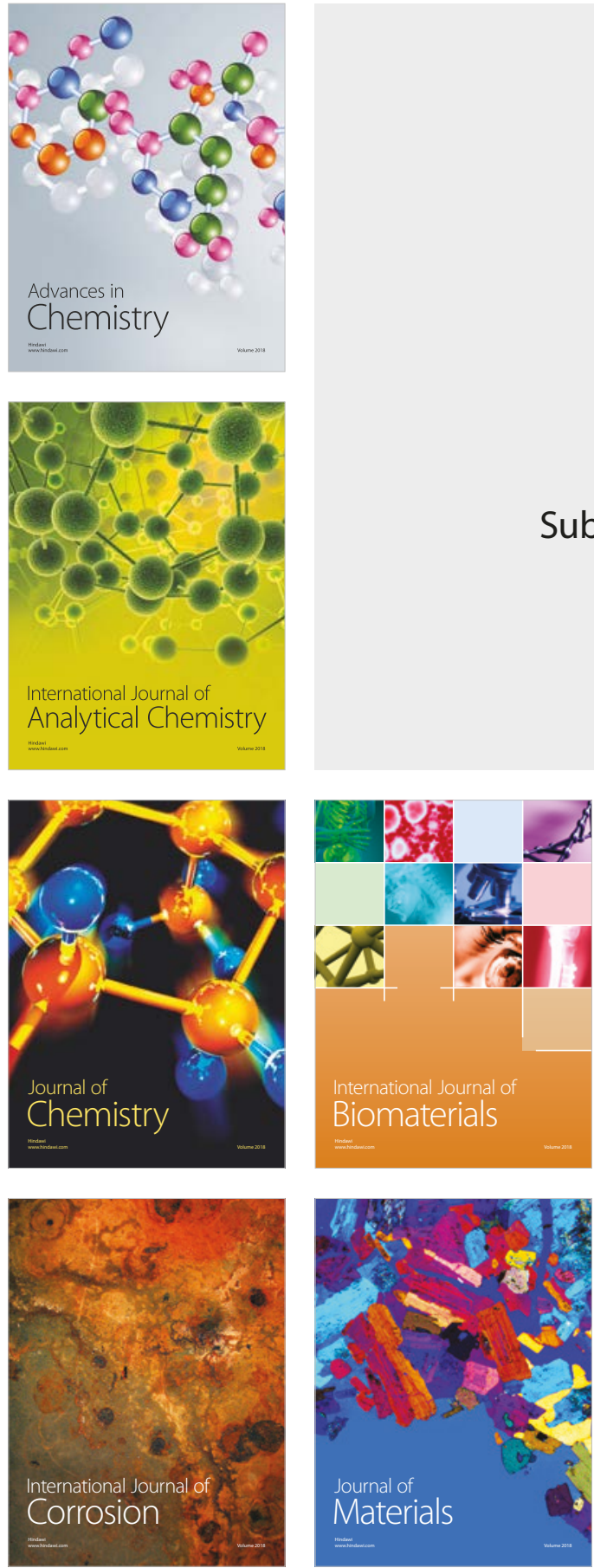

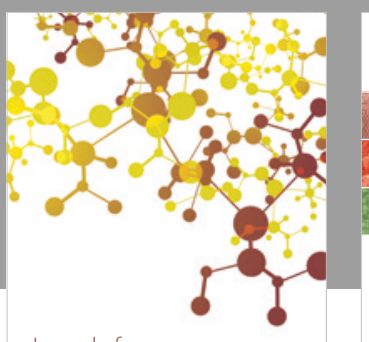

Journal of

Applied Chemistry
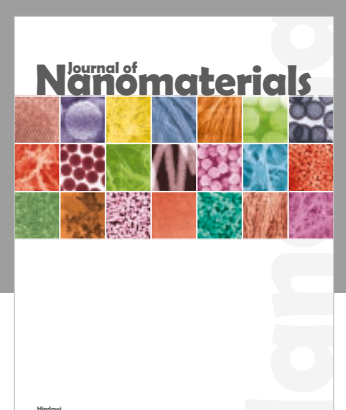

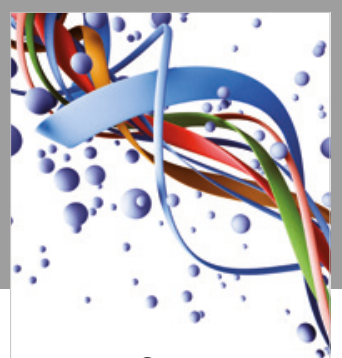

Scientifica

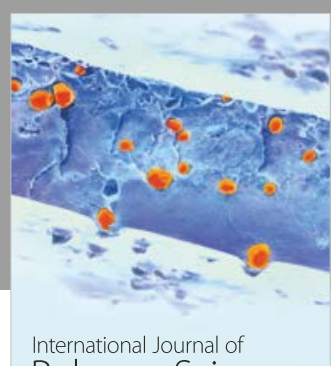

Polymer Science

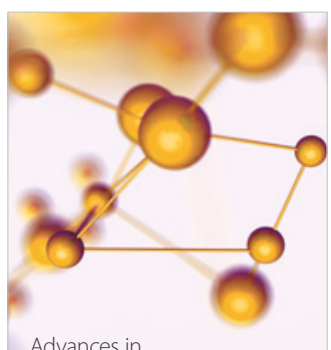

Physical Chemistry
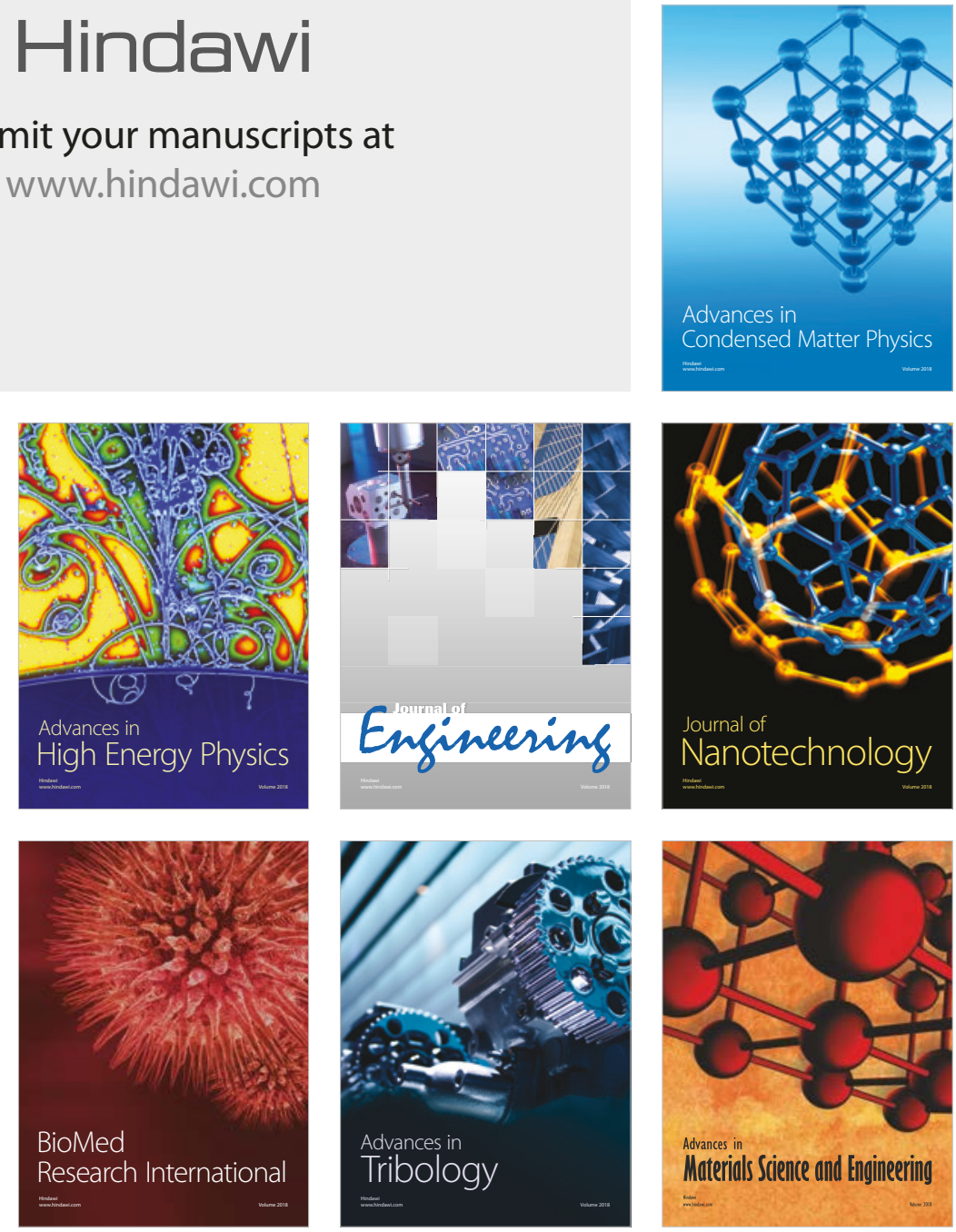